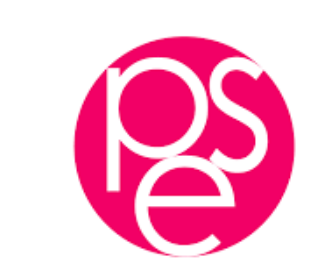

PARIS SCHOOL OF ECONOMICS
ECOLE D'ECONOMIE DEPARIS

WORKING PAPER Nº $2021-02$

On the market structure of central counterparties in the EU

Gabrielle Demange

Thibaut Piquard

JEL Codes: G20, G23, G18, G33

Keywords:

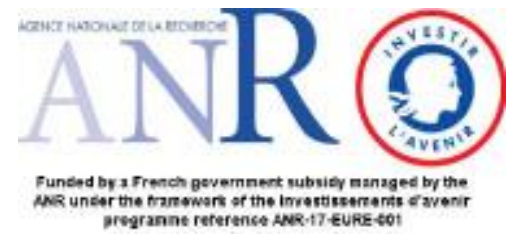




\title{
On the market structure of central counterparties in the $\mathrm{EU}^{*}$
}

\section{Gabrielle Demange $^{\dagger} \quad$ Thibaut Piquard ${ }^{\ddagger}$}

January 12, 2021

\begin{abstract}
New regulations promote the role of Central Counter-Parties as insurers of counterparty risk to stabilize derivative markets. Most CCPs are for-profit institutions, competing for profits and market shares. Whether competition is harmful or beneficial to efficiency and financial stability is debatable, leading to different positions in the US and the EU. Assessing the impact of competition between CCPs is complex because of the many dimensions involved in their policies and the heterogeneity of their potential users, ranging from main intermediaries (the dealers) to final clients. We first review the business model of CCPs and illustrate the dimensions on which CCPs compete by gathering EU data on CCPs, their scopes, their clients and members. We then focus on the clearing of CDS by providing an empirical analysis of on the choices of CCPs by the main dealers.
\end{abstract}

\section{J.E.L. Codes: G20, G23, G18, G33.}

Keywords: central counter-party, central clearing, competition, dealers, collateral.

*This work has been funded by the grant Firr of Agence Nationale de la Recherche, ANR-18-CE260015-01 and the EUR grant ANR-17-EURE-0001 .

${ }^{\dagger}$ Paris School of Economics-EHESS, 48 Boulevard Jourdan 75014 Paris, France, demange@pse.ens.fr

${ }^{\ddagger}$ Paris School of Economics and Banque de France, thibaut.piquard@gmail.com 


\section{Introduction}

The G20 in Pittsburgh in 2009 have been pushing for profound changes in the organization of markets for derivatives to limit the complexity and opacity of contracts between financial institutions, and to better control contagion effects. In that purpose, regulators mandated the use of Central Counter-Parties (hereafter CCP) for transactions on major standardized derivatives. The main economic function of a $\mathrm{CCP}$ is to insure each party in a transaction against the default of its counterparty -the counterparty risk- during the whole life of the derivative contract. ${ }^{1}$

Although CCPs are called to play a crucial role, there are concerns about their effectiveness in preventing market disruptions, as they are becoming major systemic institutions. There is also a debate on the appropriate competition level for central clearing. The EU and the US take different positions. In the US, the Department of Justice advocates in 2007 for a single CCP for clearing futures, or at least for a full 'interchangeability', which would have similar effects. At the opposite, the European Market Infrastructure Regulation (EMIR 2012) mandates central clearing on a product only if at least two CCPs are authorised in the EU. ${ }^{2}$ In this paper, we provide an empirical assessment of the state of competition between CCPs in the EU.

Leaving aside political concerns, the current economic debate regarding the market structure of central clearing bears mainly on the benefits expected from limited competition -improved efficiency in insurance, reduction of exposure due to netting practicesand the losses associated to monopoly rents. Central clearing provides insurance against counterparty risks. If these risks are mainly idiosyncratic, a few CCPs achieve a better risk pooling. The netting practice cancels part of the exposure of institutions that have both long and short positions, thereby diminishing the overall exposure to counterparty risk. This effect, referred to as netting efficiency, directly translates into a reduction of the collateral required by a CCP to cover its counterparty risk. Netting efficiency mechanically reduces the (opportunity) cost of collateral for the institutions: the more extensive the netting, the less the exposures are, hence the less the collateral costs. As a

\footnotetext{
${ }^{1}$ For a comprehensive description of central counterparties, see Pirrong (2011) or the BIS discussion paper (2010). Vuillemey (2019) analyzes the economic impact of the Caisse de Liquidation des Affaires en Marchandises created in Le Havre (France) in 1882 by traders on coffee futures.

${ }^{2}$ Though, Coeuré (2014), a EU regulator, has voiced concerns that competition between CCPs could lead to a race to the bottom regarding their risk management practices. Also, the Committee on Payment and Settlement Systems (part of BIS) (2010) discusses the lessons to draw on the traditional models of horizontal and vertical differentiation.
} 
result, central clearing generates network effects and presents natural monopoly features: a larger membership induces a larger reduction in collateral costs because contracting institutions are more likely to be members of the CCP. The same argument applies not only to the clearing of a single product but also to multiple correlated products: the requested collateral for a portfolio is less than the sum of the cost of clearing each product. Thus, insurance efficiency and network effects call for a limited number of CCPs, each having a large number of members and clients, and clearing a large number of products. A monopolist, however, would extract rents by increasing the fees charged for the clearing services, possibly diminishing the incentives to clear for a large number of institutions. Evaluating the trade-offs between these effects is not easy, which might explain why there is no unanimous regulatory doctrine. The impact of competition between CCPs cannot be assessed by transposing standard imperfect competition models because CCP's policies (or strategies) are complex, involving several dimensions and they directly deals with a very limited set of financial institutions.

A CCP's policy primarily aims at avoiding its own failure caused by the default of one or several of the financial institutions it insures. To manage this risk, a CCP screens its members, asks for various guarantees in the form of collateral (contributions to a default fund, initial and variation margins along the life of a contract), determines the set of assets it clears (its scope) and decides on the extent of netting across these assets (multinetting). A CCP also charges fees, which, strictly speaking, are not risk management tools, but contribute to the CCP's profit and soundness.

We first provide a detailed analysis of the policies, market shares and scopes of the CCPs authorized in the EU on some asset classes, using public data on the CCPs authorized in the EU. Our analysis suggests that competition takes place along several dimensions: horizontal, vertical, and scope.

Second, we study more closely the demand for clearing from major dealers. The overlapping membership of CCPs indeed constitutes a specific feature of current central clearing. A very limited set of financial institutions (called clearing members) directly uses a CCP, for their own account or for other institutions (clients). At the core, the major dealers are members of all the CCPs trading a given class of assets, and use them alternatively. We analyze which factors influence their choice on the CDS indices, using our access to derivative transactions reported to Trade Repositories (TR) under EMIR through Banque de France (see details in the Appendix). The choice of a CCP for clearing a given transaction is made by the pair of buyer and seller involved in the transaction. We 
test a stylized model restricting to pairs who participate actively in two CCPs at least. ${ }^{3}$ They share 14 common counterparties, all of them being major systemic institutions (G-SIB banks as defined by the Financial Stability Board) except one. Transactions cleared in the interdealer market exhibit some geographical segmentation. Furthermore, a substantial proportion of dealers' pairs use almost one CCP to clear their transactions. Apart from location, we test a model where pairs' decisions result from an evaluation and comparison of the costs of clearing on each CCP. Costs are composed of fees, cost of exposure to the CCP and collateral costs. We do not have access to collateral costs and proxy their variation by considering the positions of the buyer and the seller since the change in the requested collateral due to the observed transaction at a given date is computed on the basis of the whole portfolio of each trader. Our main results are as follows. Which CCP is chosen by a pair relates to the notional of the transaction being cleared, two indicators on the CCPs and the volatility index, but is not influenced by the buyer and seller's positions. The interpretations are the following ones: we argue that differences in fees between the two CCPs might explain why a CCP is relatively more chosen when the transaction is large. A first CCP's indicator is the ratio of the default fund over the largest stress loss (called the Cover2), which indicates its resilience to members' defaults. The ratio is very significant and positive in all our specifications: pairs choose relatively more a CCP whose ratio is higher relatively to the other. The second CCP's indicator is the ratio of prefunded resources (default fund and initial margins) over the CCPs open interest. This ratio is also very significant and negative; suggesting that the changes in this ratio are due to adverse changes in the pools of the CCPs members triggering an increase in prefunded resources. Finally, the fact that buyer and seller's positions are not significant suggests that collateral costs do not determine the choice of the CCPs. Observe that this result does not imply identical collateral policies: even if they are, different positions at the two CCPs should have an effect if traders minimize the cost of collateral.

The plan is as follows. Section 2 reviews the business model of CCPs and illustrates the dimensions on which CCPs compete by gathering public data on CCPs in the EU, their scopes, their clients and members. Section 3 provides statistics on dealers and CCPs on CDS. Section 4 estimate the determinants of choices by pairs of dealers who clear on several CCPs. Section 5 briefly draws policy implications based on these results. The

\footnotetext{
${ }^{3}$ This eliminates ICE-US, which has a low market share and is used only by pairs involving a US dealer.
} 
Appendix section 6 provides a glossary describing technical terms, gathers some tables figures and results.

Related literature Our paper relates to studies on competition between financial infrastructures, the incentives of institutions to clear, the netting efficiency and cost of collateral.

There is little research on competition between CCPs. Zhu (2011) documents stark competition in fees between European CCPs clearing equity. Abruzzo and Park (2014) study how expected changes in product's volatility impact the margins set by CME, a main CCP on futures and analyze competition in margin between CME and ICE, relying on daily data on margins and the gross volumes of each CCP. They show that margin requirements react to the margin difference between the two CCPs, suggesting competition in margins. Our empirical analysis differs as we focus on the demand of major dealers, who are members of the two main CCPs on CDS, using detailed transaction data by pairs of dealers.

Competition between exchanges shares similar features with competition between CCPs, due to network effects. Such effects favor the concentration of membership on a single CCP, absent differentiation characteristics. Concentration explains the reversal in market share from the London exchange to the German entrant exchange for the exchange on the Bund when deregulation made it possible, as documented by Cantillon and Yin (2008). The trend in the market shares between LCH SA and ICE-EU on three CDS indices may suggest concentration on LCH SA. Such a concentration is also observed at the product level, where ICE is predominant on single name indices.

A few recent papers investigate the dimensions of differentiation between CCPs. Anderson and Joeveer (2014) discuss horizontal differentiation along geographic or product lines and conduct simulations to compare bilateral clearing, local central clearing per area and global central clearing on OTC markets. The global one requires less collateral than the local one due to improved netting but accepts only high quality collateral so may not dominate. Armakola and Laurent (2015) investigate a 'vertical' differentiation dimension, by assessing the soundness of the members of 8 European and 5 US CCPs. Their results indicate a strong heterogeneity in the distributions of the members' credit ratings, suggesting differences in screening and pricing policies generating sorting. Finally, to our knowledge, competition between CCPs over the scope of the cleared products has not been studied so far. A CCP with a large scope provides a competitive advantage due to 
a reduction in collateral costs allowed by extended multi-netting.

The advantages of central clearing over bilateral one are subject to debate. Ghamani and Glasserman (2017) compare in detail the two organizations, incorporating the differences in the requested collateral and the capital charges due to the exposures to their counterparties (contracting institutions under bilateral clearing or CCPs under central clearing). Their simulations show that central clearing might be more costly due to higher capital charges in some cases. This relates to our result showing that CCPs robustness partly explains dealers choices between two CCPs. Bellia, Panzica, Pelizzon, and Peltonen (2018) provide an empirical study on the decision to clear CDS on sovereign bonds (French, German and Italian), for which clearing is not mandatory. The proportion of cleared products is small, which suggests that central clearing is more costly than bilateral clearing. They also show that a member is more likely to clear when this decreases its net position at the CCP. We do not find such effect, but our analysis bears on the choice between two CCPs. The saving on collateral cost induced by netting and multi-netting have been investigated by Duffie and Zhu (2011), Duffie, Scheicher and Vuillemey (2015), and Cont and Kokholm (2014). These studies bear on the collateral costs, given a scope of products offered by a CCP.

\section{The baselines of competition between CCPs}

\subsection{The clearing business}

We briefly describe the business model of CCPs, emphasizing their specificities. We focus on the clearing of derivatives.

After two institutions have traded a derivative contract, bilaterally or through an exchange, they can choose (or are mandated) to clear their contract through a CCP. CCPs provides two services to financial institutions: insurance against counterparty risk and netting of positions. First, CCPs act as intermediaries in the transaction and stand as the counterparty of both the buyer and the seller. This process is called the novation. By doing so, the initial contract between the two parties cancels out and gives rise to two new contracts from each counterparty to the CCP. The institutions' exposures to their counterparties thus turn into an Exposure to the CCP. As a result, the CCP pools the idiosyncratic parts of counterparties' risk. Second, CCPs net exposures from derivative transactions. Netting decreases the exposures of institutions that are both long and short. 
Figure 1 illustrates the novation and netting processes. Through novation, institution $B$ has no direct exposure to $A$ and $C$ in the case of central clearing. Because of netting, institution $A$ exposure to the CCP is null.

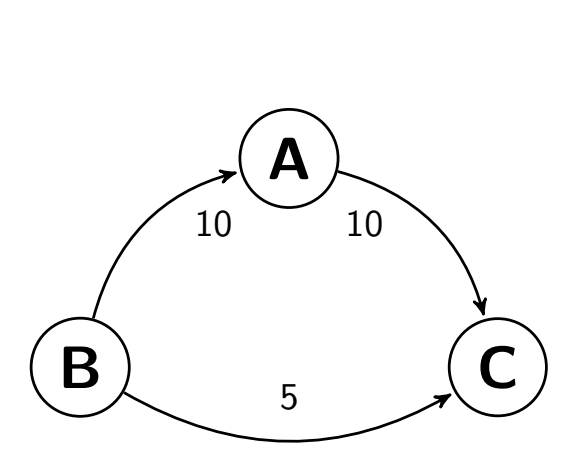

(a) Bilateral clearing

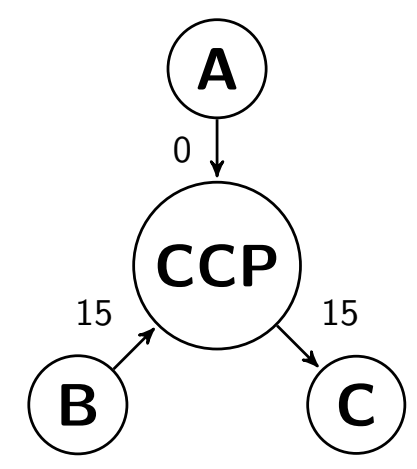

(b) Central clearing

Figure 1 - A stylized example of central clearing An arrow from $X$ to $Y$ is a claim from institution $X$ on $Y$.

An important element in the business of CCPs is that they contract directly with only a limited number of financial institutions, leading to what is referred to as a two-tier structure.

The two-tier structure Figure 2 presents this usual pattern as a hybrid two-tier structure. The CCP contracts with a limited number of institutions called clearing members (CM). These are typically large institutions that contract in turn with their customers. Therefore, the CMs insure them against the default of their counterparties. The global systemically important banks are CMs of most CCPs, except the regional ones. This structure matters for insurance, especially because of netting. If two customers of the same CM enter into a derivative contract, then the net position of the $\mathrm{CM}$ at the $\mathrm{CCP}$ on this transaction is null. Netting is thus crucial for large intermediaries involved in transactions in opposite directions.

CCP policies To conduct their business and manage their risks, CCPs employ a variety of tools we call the "CCP policies". ${ }^{4}$ Such a policy is a bundle of (i) fees, (ii) collateral requirements, (iii) access criteria for members, and (iv) scope of products eligible for clearing.

\footnotetext{
${ }^{4}$ These policies apply to members and their clients.
} 


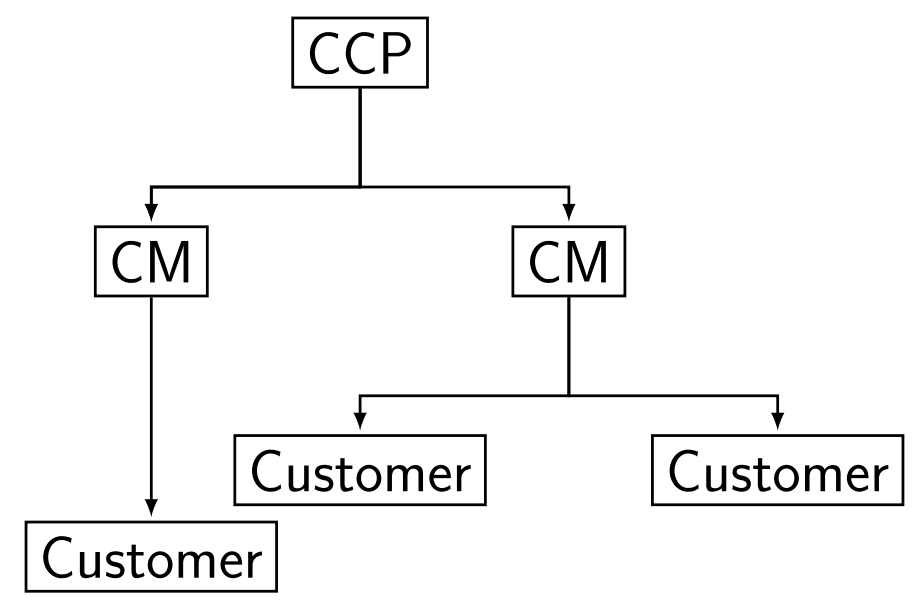

Figure 2 - Simplified two-tier structure of central clearing Note: CCP: central counterparty, CM: clearing member.

First, CCPs collects fees from their members. A member's fees are made of a fixed and a variable part, which is proportional to its total Notional cleared by the CCP. Second, to manage counterparty risk, CCP require collateral from their members: initial margins (IM) at the onset of the contract to account for the cost of liquidating the contract in case a counterparty fails, cash variation margins on a daily basis that stick to the contract changes in value, and contributions to a default fund (DF). Unlike initial and variation margins, the default fund is a mutualized resource: CCPs can draw into it to replenish a member's losses in excess of initial margins. In addition, the regulation grants the right for CCPs to require additional collateral from their members if the former prefunded resources are not sufficient to cover losses. ${ }^{5}$ Third, CCPs determine the access criteria for new members through the screening of their creditworthiness. These admission criteria include hard criteria (minimum capital and fees) but also soft criteria such as the requirement for members to have a qualified management. ${ }^{6}$ Fourth, CCPs set the scope of products eligible for clearing.

These elements of CCPs' policies interact in setting the price and quality of the services provided by CCPs, affecting the incentives for institutions to clear. First, the price paid by members is made of fees and the cost of collateral required by the CCP. The structure of the fees differ across CCPs, not only in their levels but also on the weight set on

\footnotetext{
${ }^{5}$ After the default fund is exhausted, CCPs also ask members to replenish the default fund. This happened after the failure of a rogue trader on the Nasdaq OMX (see the Financial Times (2018) paper for more information), or after the failure of a securities firm on the Korea Exchange, e.g. Vaghela (2014).

${ }^{6}$ For example, Eurex Clearing requires clearing members to have at least one "qualified clearing staff" that has passed exams prepared by Eurex (reference here).
} 
the fixed part variable. As the CCPs must pay back collateral revenues to members, the cost of collateral stems from liquidation costs of illiquid securities to purchase liquid collateral, or the opportunity cost of frozen collateral at the CCP. Second, the quality of the insurance provided against counterparty risk results from collateral requirements, access criteria for new members, and the scope of products. The quality is increasing in the total amount of collateral collected from members, which is costly for them. Hence, decreasing collateral requirements (in their amount or quality) decreases the price of the clearing service, but drives down the quality of the insurance against counterparty risk. Finally, increasing the scope of products attracts new transactions and directly affects the opportunities for cross-netting provided by CCPs. Cross-netting allows CCPs members to calculate their collateral requirements on a portfolio basis rather than on a position basis. Hence, institutions can take advantage of correlations among the positions from their portfolio to reduce their collateral requirements. Therefore, the opportunities for cross-netting are a key incentive to clear at a CCP because they decrease the cost of collateral.

\subsection{The dimensions of competition between CCPs}

CCPs' policies affect institutions differentially, determining the type and extent of competition. We present descriptive evidence on two asset classes, interest rate and credit derivatives.

Horizontal differentiation In the context of central clearing, the transportation costs from Hotelling model can be interpreted as (i) transaction costs between institutions and CCPs and (ii) specific expertise to clear some products.

Transaction costs differ across institutions and the CCPs they are allowed to use. Previous national regulations were more restrictive than now, ${ }^{7}$ thereby creating strong relationships between members and CCPs in the same geographical area. Geographical differentiation has thus induced differences in information between CCPs regarding the creditworthiness of institutions. The farer an institution is from a CCP, the lower the precision of the information between the CCP and the institution. For example, a German CCP might be better suited to assess the counterparty risk of a German institution rather

\footnotetext{
${ }^{7}$ Now, the European Securities and Markets Authority (ESMA) determines the CCPs authorized to operate all over the EU per asset classes.
} 
than a Polish one, and vice versa. We gather anecdotal evidence of such a geographical differentiation using hand collected data on contractual linkages between CCPs and their members from March 2017. We consider the market for interest rate derivatives, in which the diversity of institutions types (banks, insurers, funds) and size leads to substantial heterogeneity in counterparty risk profiles, hence differences in information precision. We present in Figure 3 how single members of CCPs split by country. For example, 14 Swiss institutions are members of a single CCP. All of these institutions but one are members of Eurex Clearing, the German CCP. Figure 3 shows there is a substantial geographical differentiation between CCPs for single membership. Single members of Eurex Clearing are mostly located into German speaking countries: Germany, Switzerland, and Austria. Similarly, all members of the Nasdaq OMX are located in Nordic countries: Denmark, Island, and Sweden. Other markets such as repo, equity, and foreign exchange also exhibit similar geographical differentiation. Figure 6 in the appendix presents the full network of contractual linkages between CCPs and members. In addition to Figure 3, it displays the core banks, which are CM of most CCPs.

Different expertise to clear products can lead to segmentation of product lines between CCPs. Derivatives payoffs are heterogeneous across products, and central counterparties have different expertise to assess their distributions, especially their tail risks. For example, European CCPs could have more skills to manage the risk of complex European derivatives rather than American ones. Figure 7 from the Appendix reports the Index CDS eligible for clearing at the two CCPs offering this service, ICE (group) and LCH SA. While the five largest Index CDS on Figure 4 are eligible for clearing at the two CCPs, the other products are eligible for clearing at only one CCP. This provides anecdotal evidence of horizontal differentiation between lines of products cleared by CCPs. Taking into account open interest (OI) reveal even more segmentation between product lines. Figure 4 presents open interest of cleared Index CDS split by CCP and Index names, as of April 2019. While LCH SA offers clearing of North American CDX (cdx.na.hy and cdx.na.ig on Figure 4), its market share for these products is almost null. In addition, Table 8 from the Appendix reveals that the two CCPs effectively clear only $34 \%$ of single name CDS in numbers. Even if these CDS account for $61 \%$ of total open interest cleared by those two CCPs, this result also provides anecdotal evidence regarding the existence of segmentation for single name CDS. 


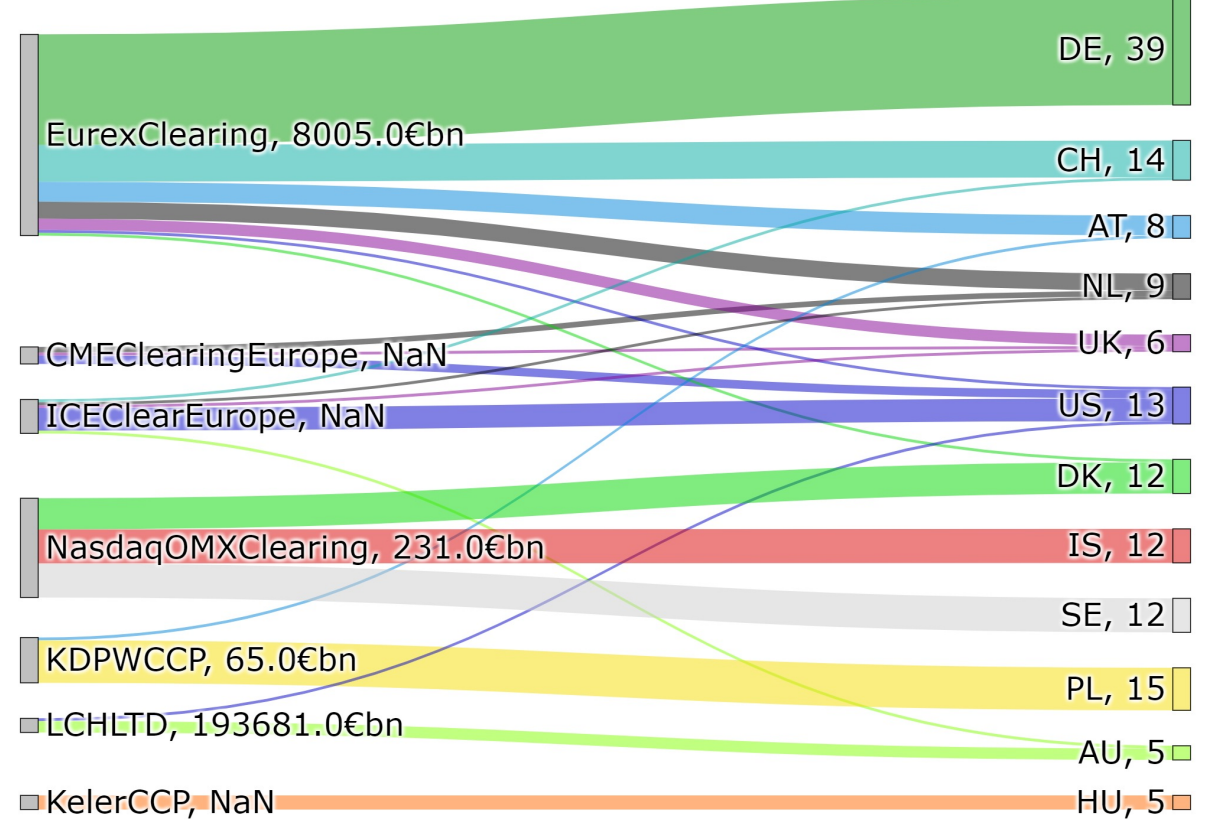

Figure 3 - Interest rate derivatives, number of single CCP members per country

Sankey diagram of the number of single members by pair of CCP-country. The figure also presents the open interest (OI) from CCPs in interest derivatives if available. Each country has a given color and its ISO code. The number of single members per country is displayed next to countries names. Flows of members between CCPs and countries are scaled by the number of single members per CCP, and coloured by country. Source: CCPs disclosure, as of March 2017.

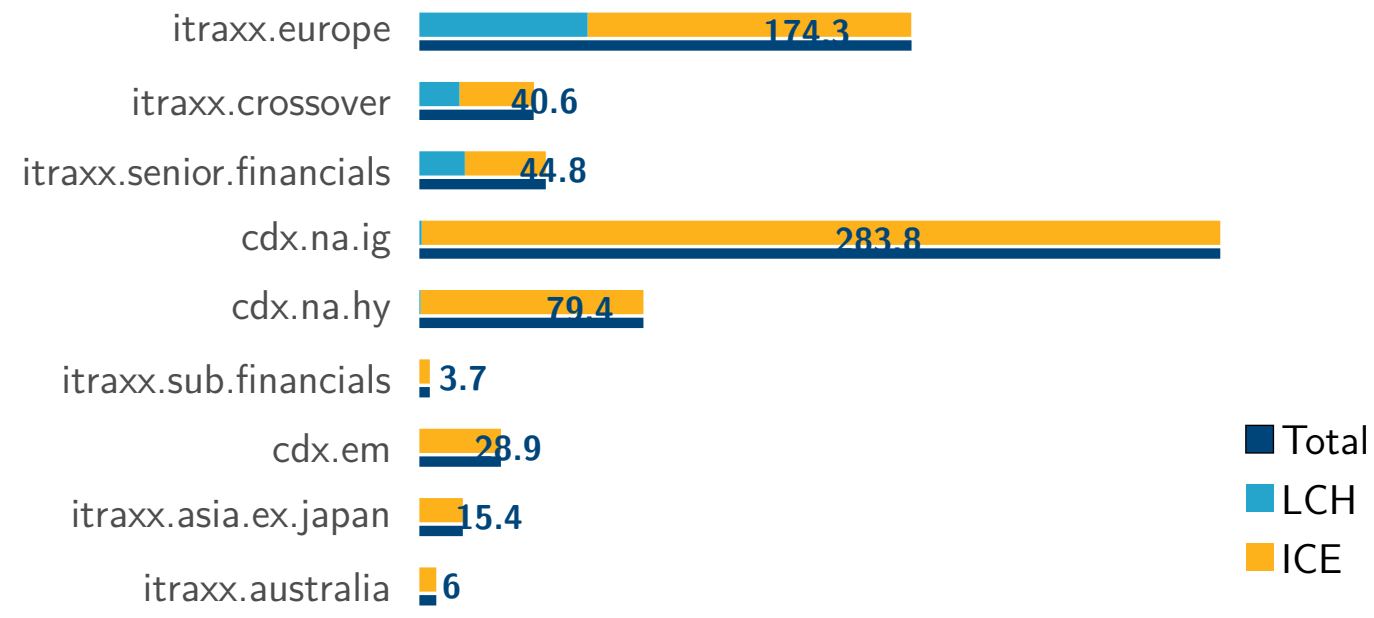

Figure 4 - Credit Default Swaps, Open Interest split by CCP and Index name

Open interest (OI) in €billion. Source: CCPs disclosure, as of April 2019. ICE OI is the sum of ICE Clear Credit and ICE Clear Europe OI. 
Vertical differentiation We focus on the quality of insurance against counterparty risk, leaving aside other quality characteristics such as facilities, reporting, relationships. As explained in Section 2, CCPs improve the quality of their insurance against counterparty risk by increasing their prefunded resources: margin requirements and contributions to the default fund, and the quality of the collateral they accept. They also improve their quality by choosing members of higher creditworthiness through the screening of new members. The quality of the insurance service provided by the CCP is costly in terms of collateral but limits the use of the default fund in case of failure by other members. These policies affect members differentially, because they differ in their risk aversion, the regulatory constraints they face, and their assets eligible as collateral. Vertical differentiation between CCPs may arise through this channel.

We present two measures of the quality of insurance against counterparty risk, the ratio of the largest stress loss over the default fund, and the total prefunded resources over the open interest. Variables include default fund (DF), initial margins (IM), the open interest (OI), and the largest stress loss for which the computation is performed over all the products and members in a given asset class. Default fund (DF) and initial margins (IM) together are pre-funded resources that can be used by the CCP in case of a member's default ${ }^{8}$ The largest stress loss is defined as the maximum of the largest loss caused by the default of the first or the second and third largest members in excess of their initial margins (Cover 2 scenario).

Table 1 reports measures of the quality of European CCPs insurance against counterparty risk for the clearing of commodities and CDS as of 2018Q3. These measures show that CCPs provide different levels of insurance against counterparty risk, which tends to signal vertical differentiation. First, the table reports the ratio of the default fund over the largest stress loss (the Cover2 ratio). By definition, the default fund should withstand extreme shortfalls from the Cover2 scenario. CCPs providing similar insurance against counterparty risk should have similar ratios. There is substantial heterogeneity between the ratios reported by CCPs, ranging from 0.99 to 1.60 for commodities. Second, the table reports the ratios of prefunded resources (DF and IM) over the open interest (the prefunded ratio). Still, they heterogeneously range from $7.2 \%$ to $36.7 \%$ for commodities and from $1.6 \%$ to $2.8 \%$ for CDS. There is no clear measure of a CCP quality. While the prefunded ratio stands on clear and measurable balance sheet aggregates, the measure

\footnotetext{
${ }^{8}$ CCPs specify how members' losses exceeding their margins are allocated between participants, see Elliot (2013) e.g. These specifications are referred to loss-allocation rules or waterfall.
} 
depends on the mix of products and clients for a CCP and an asset class. In contrast, the Cover2 ratio does not depend on the product mix. However, it is model dependent since CCPs compute this measure.

\begin{tabular}{llrr}
\hline & & DF & $\frac{I M+D F}{\text { Cover2 }}$ \\
\hline Commodities & & & \\
& & & \\
& Nasdaq OMX & 1.12 & $19.1 \%$ \\
& ECC & 1.60 & $N A$ \\
& OMI Clear & 0.99 & $23.6 \%$ \\
& LME & 1.47 & $7.2 \%$ \\
& BME Clearing & 1.1 & $36.7 \%$ \\
\hline CDS & & & \\
& LCH SA & 5.82 & $2.7 \%$ \\
& ICE-EU & 53.5 & $1.6 \%$ \\
& ICE-US & 13.1 & $2.8 \%$ \\
\hline
\end{tabular}

Table 1 - Default fund over largest stress loss in excess of initial margins (Cover2 ratio), and prefunded default resources over gross notional outstanding (prefunded ratio).

Sources: CCPs' IOSCO quantitative disclosure, 2018Q3. The open interest in the CDS market is similar to the gross outstanding in the market for commodities.

In our analysis of CDS in Section 3, we use both the Cover2 and the prefunded ratio. They come from CCPs quarter variables in the IOSCO quantitative disclosure from 2015Q3 to 2020Q2. Figures 8 and 9 in the Appendix present the evolution of these ratios for CCPs in the CDS asset class, which are computed for the whole portfolio of CDS and members. The prefunded ratios of two CCPs range from $2.2 \%$ to $3 \%$ along the period while the one of the last CCP is close to $1.5 \%$.

Scope of instruments eligible for clearing CCPs are multi-product firms, as they offer clearing services for a range of asset classes. For example, LCH SA offers clearing services for CDS, repos and fixed income, commodities, cash equities, and equity derivatives. Each class is composed of products, which have correlated payoffs. There are thus two levels of competition on the range of offered clearing services: on the asset classes and within an asset class. The previous examples bear only on within asset class differentiation. As said in the related literature, a larger scope offered by a CCP expands the opportunities for cross-netting within an asset class. It decreases the amount of collateral asked to members, hence the cost to clear their contracts through it. Therefore, a larger 
scope provides a clear cost advantage over competing central counterparties. However, this comes at a risk for CCPs. The validity of cross-margining models such as SPAN or those based on VAR techniques heavily depends on how relevant historical correlations between products are. Changes in correlation across products can endanger CCPs creditworthiness. As a result, increasing the scope of cleared products reduces the cost incurred by members to clear their transactions but also potentially hampers the quality of the service provided by the CCP.

\section{Clearing of CDS transactions in the EU}

In the following, we focus on the CDS markets in the EU. There are three CCPs belonging to two groups active in the European CDS market: ICE Clear Credit, ICE Clear Europe, and LCH SA. A priori, CCPs compete on two dimensions: to clear transactions between existing members and to attract new members. We focus on competition on the clearing of transactions in the inter-dealer market. All dealers are members of at least two CCPs at least and all CCPs clear the most traded products. This allows us to investigate why pairs of dealers choose to clear a given transaction through a CCP instead of another one. We do not investigate the decision to be a member or not: our dataset provides too little information to identify the determinants of membership at CCPs. ${ }^{9}$

We describe the dataset and provide some descriptive statistics concerning the geographical differentiation and the observed choices of CCPs to clear transactions.

Transactions The analysis builds upon the cleaned dataset of EMIR transactions from DTCC. We focus on inter-dealer transactions for their own account ${ }^{10}$ cleared through central counterparties. We restrict the dataset to three CDS Indices on which the competition between CCPs is effective. According to Figure 4, these products are the Itraxx Europe, Itraxx crossover, and Itraxx senior financials. For these products, we have all transactions entered into by at least one European institution. Our data covers transactions from 01/01/2018 to 05/08/2020. The two first products are subject to the clearing obligation, but not the third one. We provide more details to the data cleaning in Appendix 6.2.

\footnotetext{
${ }^{9}$ Since major dealers are members of the main CCPs, we would need to include clients membership. However, client clearing at LCH SA is anecdotal and initial margins provided by clients are only $3 \%$ of the total. Source: IOSCO reporting 2019Q1.

${ }^{10}$ Dealers also clear transactions on behalf of their clients. We do not consider them as the clients may influence the choice of the CCP.
} 
Active Dealers Table 9 from the Appendix reports the active dealers affiliated entities in our sample and their respective jurisdictions. Main jurisdictions include the US, the EuroZone and the UK.

Geographic segmentation Two counterparties clearing a transaction must agree on the same CCP. ${ }^{11}$ The pair of counterparties thus make the CCP's choice. Table 2 reports how pairs of dealers choose their CCPs according to the geographic area of dealers. Dealers and CCPs locate in three geographic areas: the Eurozone (EZ), GB, and the US. The first column reports the percentage of notional cleared by dealers from the same geographic area with a CCP from the same geographic zone. These are EZ dealers clearing at LCH SA, GB dealers clearing at ICE-EU and pairs with at least one US dealer clearing at ICEUS. The second column reports the percentage of notional cleared by dealers from the same geographic area at a CCP from another area. The last column reports the remaining percentage of notional, the one for which dealers are not from the same geographic area. The majority of transactions take place between dealers from different areas. Choice of CCPs exhibits a small geographic segmentation for transactions between dealers from the same area: for the Itraxx Europe, 26.5\% of notional clears at a CCP from the same area, while $22.8 \%$ clears at a CCP from a different area. This result holds for the two other products.

\begin{tabular}{l|cccc}
\hline \multirow{2}{*}{ Product } & $\begin{array}{c}\text { Same geographic } \\
\text { zone for dealers } \\
\text { and CCP }\end{array}$ & $\begin{array}{c}\text { Same geographic } \\
\text { zone for dealers, } \\
\text { not for CCP }\end{array}$ & $\begin{array}{c}\text { Remaining } \\
\text { transactions }\end{array}$ & Notional \\
\hline Itraxx Europe & $26.5 \%$ & $22.8 \%$ & $50.7 \%$ & 535.0 \\
Itraxx crossover & $23.4 \%$ & $19.2 \%$ & $57.4 \%$ & 119.2 \\
Itraxx senior financials & $22.0 \%$ & $19.0 \%$ & $58.9 \%$ & 95.1 \\
\hline
\end{tabular}

Table 2 - Inter-dealer choice of CCP by geographic zone, percentage of total notional on the period.

Geographic zones are ZE, GB and the US. Transactions between dealers from the same geographic zone are between ZE-ZE, GB-GB or with a US dealer. CCPs belong to either ZE (LCH SA), GB (ICE-EU) or the US (ICE-US). Remaining transactions are between dealers from different geographic zone without a US counterparty. Notional is in €billion.

Choice of CCPs by pairs of dealers To complement the geographic analysis of trades, we study the number of CCPs that pairs of dealers use. For each product, Table 3

\footnotetext{
${ }^{11}$ There are no agreements, referred to as interoperability, between the CCPs clearing CDS in Europe.
} 
presents the percentage of CCPs used for clearing by pairs of dealers, and the total numbers of pairs clearing the product. A large percentage of pairs of dealers, between $25.5 \%$ and $45.5 \%$, clear their trades at a single CCP. Clearing on a single CCP is smaller on the Itraxx Europe, the product with the highest liquidity.

\begin{tabular}{lrrrr}
\hline Number of CCPs & 1 & 2 & 3 & Number of pairs \\
\hline Itraxx Europe & $25.5 \%$ & $42.8 \%$ & $31.7 \%$ & 98 \\
Itraxx Crossover & $38.3 \%$ & $38.3 \%$ & $23.4 \%$ & 107 \\
Itraxx Senior Financials & $45.5 \%$ & $41.8 \%$ & $12.7 \%$ & 79 \\
\hline
\end{tabular}

Table 3 - Number of CCPs chosen by pairs of dealers, percentage

For each product, the table presents the number of CCPs used by pairs of dealers in percentage, and the total number of pairs clearing the product. For example, $31.7 \%$ of pairs of dealers cleared Itraxx Europe at three CCPs along the period.

To complete these results, we provide information on how transactions effectively split across CCPs. On a given product, we define $s_{j}$, the Herfindahl-Hirschman Index (HHI) of CCPs at pair of dealers $j$ level. $s_{j}$ writes:

$$
s_{j}=\sum_{i \in\{C C P s\}} s_{i, j}^{2}
$$

with $s_{i, j}$ the market share of CCP $i$ at the pair $j$ level. We compute market shares over the notional cleared. Figure 5 presents the cumulative distribution of HHI across pairs of dealers. A high HHI means a pair of dealers use almost only one CCP, while a low HHI means that transactions split on several CCPs. HHI from Figure 5 are not normalized. They are bounded below by $1 / 3$, the case for which a pair of dealers equally splits transactions on three CCPs. It is also natural that the vast majority of the distributions lies above 0.5 , which is the lower bound of an HHI with pairs equally splitting transactions on two CCPs.

Figure 5 complements the results from Table 3. While the number of pairs of dealers clearing at only one CCP ranges from $25.5 \%$ to $45.5 \%$, a higher proportion of pairs effectively use almost only one CCP, with percentages of pairs having a HHI larger than 0.95 ranging from $38 \%$ to $50 \%$ across products. More striking is the case of the Itraxx Europe. Only $25.5 \%$ of pairs use only one CCP on this product, but the proportion of HHI higher than 0.95 on it is much larger: 50\%. Still, a substantial percentage of pairs have HHI smaller than 0.9 for every product. It means no CCP has a clear monopoly on 
these pairs.

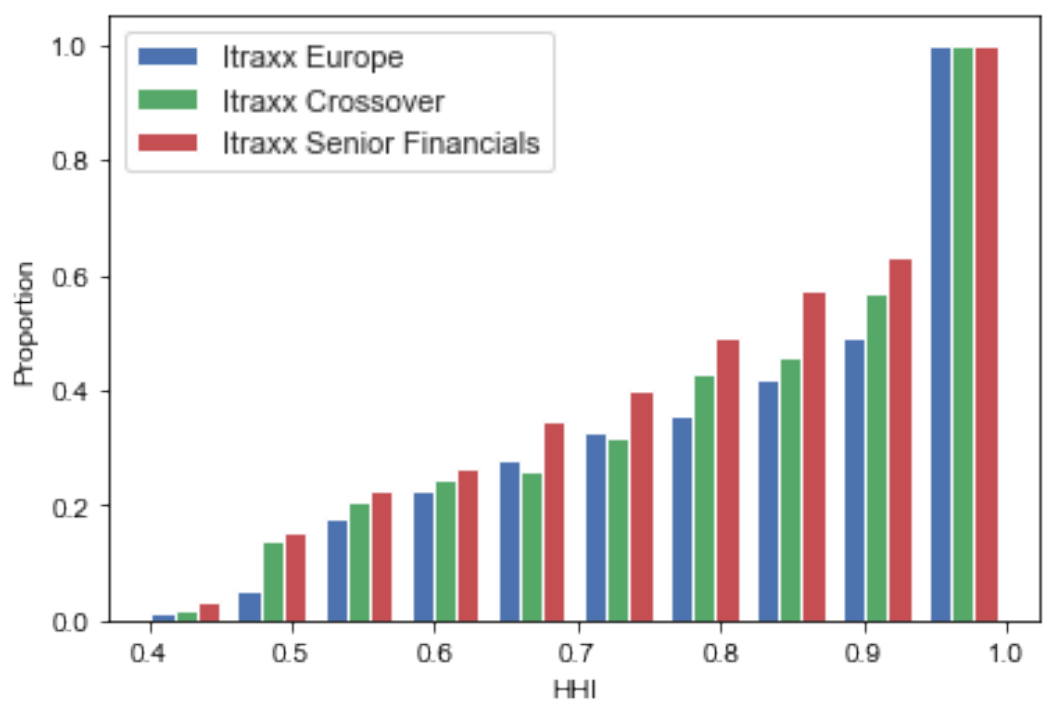

Figure 5 - Cumulative distribution of HHI split by product

HHIs are computed for each active pair of dealers during along the period.

Apart from the small geographic segmentation at stake in the choice of CCPs, the last finding from Figure 5 calls for an analysis of other determinants of the choice of CCP that we carry out in the remaining sections.

\section{Choice of CCPs: an analysis}

Our main objective is to investigate how pairs of dealers choose the CCP on which they clear a given transaction. To abstract from the geographic dimension, we eliminate the transactions involving a US dealer and run the regressions on transactions between two EU institutions (European holdings or European affiliates of foreign dealers) active on the two EU CCPs (LCH SA and ICE-EU) along the period. The reduced sample includes 16563 transactions. Subsection 4.1 presents the explanatory variables that we use in our estimation. Subsection 4.2 explains why these variables might influence pairs' choices. Subsection 4.3 presents the results. 


\subsection{Explanatory Variables}

Our main variables bear on the CCPs, the market conditions, and the dealers -their positions at the CCPs and their riskiness. In the following, CCPs are indexed by $i=1,2$.

CCP ratios. The risk of a CCP may vary overtime due to various factors such as its collateral policy and the pool of its members and clients. The Cover2 ratio defined in section, $\frac{D F}{\text { Cover } 2}$, partly captures such effect. The Cover2 ratio is a clear measure of the robustness of the CCP. As can be seen in Table 1 and Figure 8 in the Appendix, the Cover2 ratios of the two CCPs substantially differ and vary overtime. We also consider the prefunded ratio, defined as the total prefunded resources over the open interest, $\frac{D F+I M}{O I}$. The prefunded ratio is an indicator of the activity of the CCP, but not necessarily of its robustness because the open interest OI is not risk-adjusted. Keeping OI fixed, a higher ratio indicates a higher level of prefunded resources, which stems from two effects. First, the CCP policy strengthens its policy and requires a higher level of collateral against a given risk, and, second, the pool of the CCPs members and clients becomes riskier hence triggers an increase in the prefunded resources to cover the increase in risk. A larger ratio may thus indicate more robustness (safer policy) or more risk (riskier pool).

Market volatility. The CCPs adjust the margins to the overall market conditions, in particular requires higher margins in turbulent times. To account for these adjustments, we include the volatility index Vstoxx as an explanatory variable.

Dealers' positions and riskiness. The (positive) notional $x$ for the buyer represents the transaction of a pair of dealers. While dealers choose their CCP at the transaction level, the initial margin depends not only on the transaction but also on the stock of outstanding transactions. We have access to the dealer's daily Net position by product, defined as the algebraic sum of the dealer's positions with all counterparties (dealers as well as clients) for the index considered, as well as all indices. In the next section, we explain how these positions matter if dealers aim at minimizing the cost of collateral. Depending on the cost structure, different combinations of the positions matter and are introduced as explanatory variables. We consider the gap and the pair's index. They are defined as follows, denoting by $\nu_{s, i}$ and $\nu_{b, i}$ the (net) positions at $\mathrm{CCP}_{i}$ respectively for the seller and the buyer on a day.

The gap is defined for a dealer as the difference in its positions at the two CCPs: the gap for the buyer is $\delta\left(\nu_{b}\right)=\nu_{b, 2}-\nu_{b, 1}$ and for the seller $\delta\left(\nu_{s}\right)=\nu_{s, 2}-\nu_{s, 1}$. The gap matters if minimizing the total amount of required collateral is obtained by minimizing the gap 
in absolute value. In that case, a dealer aims at equalizing its positions at the two CCPs. A transaction increases or decreases a dealer's gap depending on its sign (assuming that the transaction does not affect the sign of the gap). For example, if $\delta\left(\nu_{s}\right)=\nu_{s, 2}-\nu_{s, 1}>0$ and the pair chooses $\mathrm{CCP}_{2}$ (resp $\mathrm{CCP}_{1}$ ), then the seller's gap decreases (resp. increases).

The pair index on a CCP combines the positions of both members at a CCP: the pair index on $\mathrm{CCP}_{i}, i=1,2$ is defined by $\left(\mathbf{1}_{\nu_{s, i}<0}-\mathbf{1}_{\nu_{b, i}<0}\right)$. The index is equal to 1 when the collateral of both the buyer and the seller is expected to increase if the transaction is cleared on $\mathrm{CCP}_{i}$ because each position in absolute value increases (since the seller's position is negative and the buyer's position is positive). The index is equal to -1 when the collateral of each is expected to decrease, and 0 when collateral vary in opposite directions.

Finally, CCPs may discriminate dealers and charge higher collateral to those who are riskier. A measure of the dealer's riskiness is its CDS spread. We define Spread as the dealer CDS spread deviation to the average CDS spread over the dealers (to factor out time effects).

Table 4 presents descriptive statistics for the explanatory variables. To ease coefficients interpretation, we take transaction notional in millions, dealers CDS deviation from the average dealer CDS spreads in basis point, differences in prefunded ratios in percentage points, difference in Cover2 ratio in units, and dealers' differences in net positions in billions. Variables in difference are the difference between one CCP and the other. Half of transactions notional stands between $€ 10 \mathrm{mn}$ and $€ 25 \mathrm{mn}$. The distribution of notional is skewed to large notional values. The CDS deviation spread of dealers ranges from -59 to $128 \mathrm{bps}$ in the sample, and the majority of the distribution lies in a range of $\pm 15 \mathrm{bps}$ around the null deviation spread. The difference in prefunded ratios varies from 0.48 to $1.26 \mathrm{pp}$ along the period. This is a rather large range when compared to the distribution of the prefunded ratio (from 1.4 to $3.1 \mathrm{pp}$ ). The difference in Cover2 ratios ranges from -47.7 to -7.9 . Finally, the dummies reflecting the cost of collateral at each CCP have mean and median values close to zero and enough heterogeneity in between their $25 \%$ and $75 \%$ quantiles to potentially account in the estimation.

We now present a simple test on whether dealers aim at diminishing their collateral costs simply by decreasing their gap in absolute value. Table 5 reports the proportion of times where pairs choose $\mathrm{CCP}_{2}$ or $\mathrm{CCP}_{1}$ depending on the buyer and seller's positions. Row 1 considers the case where clearing on $\mathrm{CCP}_{2}$ diminishes the positions in absolute 


\begin{tabular}{lrrrrrr}
\hline & $x(€ \mathrm{mn})$ & $C D S(\mathrm{bps})$ & $\delta\left(\frac{D F+I M}{O I}\right)(\mathrm{pp})$ & $\delta\left(\frac{D F}{\text { Cover } 2}\right)$ & $\left(\mathbf{1}_{\nu_{s, 2}<0}-\mathbf{1}_{\nu_{b, 2}<0}\right)$ & $\left(\mathbf{1}_{\nu_{s, 1}<0}-\mathbf{1}_{\nu_{b, 1}<0}\right)$ \\
\hline Min. & 0.005 & -59.8 & 0.48 & -47.7 & -1 & -1 \\
q0.25 & 10.0 & -14.3 & 0.74 & -40.6 & -1 & -1 \\
Median & 25.0 & -5.9 & 0.92 & -26.8 & 0 & 0 \\
Mean & 29.9 & 2.8 & 0.91 & -29.1 & -0.002 & -0.01 \\
q0.75 & 25.0 & 12.5 & 1.13 & -21.7 & 1 & 0 \\
Max. & 1000.0 & 128.4 & 1.26 & -7.9 & 1 & 1 \\
St dev. & 38.1 & 26.4 & 0.22 & 11.8 & 0.75 & 0.72 \\
\hline
\end{tabular}

Table 4 - Explanatory variables, descriptive statistics

value for both dealers and clearing on $\mathrm{CCP}_{1}$ increases them for both. Row 2 considers the opposite case. If dealers aim at decreasing the gap in absolute value, one should observe different conditional frequencies, with larger values in Row 1 than in Row 2 . This is not the case. Furthermore the Fisher test rejects the null hypothesis that the two conditional distributions are identical, which may even indicate the result opposite to the one expected. The test only includes positions, and need to be complemented by further estimations.

\begin{tabular}{c|ccc} 
Conditional probability & By index & All indices & 3 indices \\
\hline $\mathbf{P}\left(2\left\{\begin{array}{l}\nu_{s, 2}>0, \nu_{b, 2}<0 \\
\nu_{s, 1}<0, \nu_{b, 1}>0\end{array}\right)\right.$ & 0.75 & 0.71 & 0.71 \\
\hline $\mathbf{P}\left(2 \mid \begin{array}{l}\nu_{s, 2}<0, \nu_{b, 2}>0 \\
\nu_{s, 1}>0, \nu_{b, 1}<0\end{array}\right)$ & 0.81 & 0.78 & 0.78 \\
\hline Fisher test statistics & 3.03 & 3.62 & 3.54
\end{tabular}

Table 5 - CCP choice conditional on the sign of net positions

The table reports the frequency of choosing $\mathrm{CCP}_{2}$ or $\mathrm{CCP}_{1}$ depending on the buyer and seller's positions in two cases. Row 1 (resp. Row 2) reports the proportion of transactions where the pair chooses $\mathrm{CCP}_{2}$ when the signs of their positions could incite them to choose $\mathrm{CCP}_{2}$ (resp. $\mathrm{CCP}_{1}$ ). Net positions are computed respectively at the product level for each transaction, for all indices, or on the three indices in the sample. For a Fisher test statistics larger than 1.96, we reject the null hypothesis that the two conditional probabilities have the same distribution.

Finally, we study how the gap of a dealer varies across time between the two CCPs. Table 6 presents the regression tests and mean values of the series in the cross-section of dealers. There is substantial heterogeneity in the mean values of dealers' gaps. While 
the mean across dealers amounts to $2.73 € \mathrm{bn}$, the standard deviation is equal to 6.56. There is no large imbalance in the sign of the mean difference in net positions across dealers: the $25 \%$ quartile stands at $-1.03 €$ bn while the $75 \%$ quartile stands at $4.92 € b n$. We also study the auto-regressive properties of differences in net positions and find that they exhibit a rather high persistence: the regression coefficient from an $A R(1)$ is 0.88 on average. Their constant term is close to zero but has a strong dispersion of 0.54 . This persistence is much smaller for time series in first difference.

\begin{tabular}{l|rr|r}
\hline & $\begin{array}{c}\text { AR(1) } \\
\text { Constant }\end{array}$ & \multicolumn{1}{c}{ Mean (euro bn) } \\
\hline Mean & 0.07 & 0.88 & 2.73 \\
Std. & 0.54 & 0.11 & 6.57 \\
Min. & -1.10 & 0.68 & -5.89 \\
$25 \%$ & -0.09 & 0.82 & -1.03 \\
Median. & 0.09 & 0.94 & 0.28 \\
$75 \%$ & 0.34 & 0.95 & 4.93 \\
Max. & 0.87 & 1.01 & 16.71 \\
\hline
\end{tabular}

Table 6 - Time series properties of dealers gaps

\subsection{Dealers' costs}

We discuss why and how the explanatory variables described above may influence the choice of CCPs. As a single CCP clears a given transaction, the involved buyer and seller must choose the same CCP based on their interests, which can be divergent. Before considering the pair's choice, we describe the benefits and costs incurred by each dealer in the pair clearing a transaction on a given CCP. Specific benefits attached to a given CCP (e.g. geographical) are independent of the transaction $x$ and are incorporated in dealers' pairs fixed effects in the conducted estimations. Consider now the clearing costs.

The costs are of three different types ${ }^{12}$ composed of (1) fees, (2) the cost associated with the exposure to the chosen CCP, and (3) the opportunity cost of pledging collateral as initial margin or contribution to the CCP default fund. The dealer's incremental cost due to clearing transaction $x$ on $\mathrm{CCP}_{i}$ can be written as

$$
\Delta F_{i}(x)+\Delta K_{i}(x)+\Delta C_{i}(x)
$$

\footnotetext{
${ }^{12}$ In practice, there are numerous various costs associated to the services provided by a CCP. We roughly follow here the description in Ghamami and Glasserman (2017).
} 
where $\Delta F_{i}(x)$ is the incremental fee, $\Delta K_{i}(x)$ the incremental cost due to the exposure to $\mathrm{CCP}_{i}$, and $\Delta C_{i}(x)$ is the incremental cost of collateral. Let us examine the three terms in turn.

(1) Fees. CCPs charge fees based on the yearly cleared transactions. For a linear schedule with fee $f_{i}$ per unit, incremental fees associated to the transaction are independent on the yearly amount of dealers' transactions given by:

$$
\Delta F_{i}(x)=f_{i} x
$$

for both the buyer and the seller. Offered schedules are however more complex. LCH SA offers three schedules; two are piece-wise linear with a positive minimum and a (high) upper bound, and the other is a fixed price schedule. ICE-EU offers a unique linear schedule, steeper than those proposed by LCH SA but with a null minimum. Since we do not know which schedules the dealers choose, we include $x$ as an explanatory variable in the estimations.

(2) Cost of exposure to the CCP. This cost includes the capital charges on the overall exposure to the CCP (for a dealer subject to Basel regulation) as well as the assessed CCP's counterparty risk and activity. The capital charges are computed on the yearly exposures, so that the incremental cost $\Delta K_{i}(x)$ is unlikely to depend on the transaction $x$. The CCP's risk and activity can be assessed though the Cover2 ratio, $\frac{D F}{\text { Cover } 2}$ and the prefunded resources over open interest, $\left(\frac{D F+I M}{O I}\right)$. Furthermore, as the CCP's resources must increase in turbulent times, the ratios are affected by market volatility in a way that depends on the CCP's policy. This leads us to estimate a linear form for the cost of exposure to $\mathrm{CCP}_{i}$ :

$$
\Delta K_{i}(x)=-\alpha\left(\frac{D F}{\operatorname{Cover} 2}\right)_{i}-\beta\left(\frac{D F+I M}{O I}\right)_{i}+\gamma_{i} \text { Vstoxx }
$$

As explained previously, the Cover2 ratio is a clear measure of the robustness of the CCP, hence we expect $\alpha$ to be positive. $\gamma_{i}$ is expected to be positive and reflects the increase in the riskiness of the CCP in periods of higher volatility. The sign of $\beta$ is ambiguous and will be interpreted according to the results. The seller's incremental cost is identical.

(3) Collateral costs. The cost of collateral represents an opportunity cost for the collateral required by a CCP. ${ }^{13}$ Let the cost per unit of collateral be constant and identical

\footnotetext{
${ }^{13}$ According to Ghamami and Glasserman (2017) the BIS measures cost per unit of collateral $c_{l}=0,7$
} 
across the $\mathrm{CCPs}^{14}$ so that the collateral costs are proportional to the required margins. Let us first consider the margins requested to an average dealer, absent discrimination effects. Different CCPs may require different margins for two main reasons. First, CCPs differ in their risk acceptance and use different risk models for computing the margins. ${ }^{15}$ Second, different dealer's positions on the two CCPs result in different risk exposures for the CCPs, hence different margins. In practice, CCPs compute margins on the whole dealer's portfolio cleared in the CDS asset class, so that the collateral costs on a single transaction depend on this portfolio. We use the net positions as a proxy for the portfolios ${ }^{16}$ and conduct estimations by considering the position either on each index separately or summed on multiple index CDS (aggregated either over all CDS indices or on the three indices from the sample). Furthermore, given the asymmetric distribution of the CDS's payoffs, CCPs are more exposed on dealers with negative positions than positive ones. So given $\nu$ the dealer's net position at $\mathrm{CCP}_{i}$ on a day, we write the dealer's collateral costs $C_{i}(\nu)$ as follows

$$
\begin{aligned}
C_{i}(\nu) & =C_{i}^{+}(\nu) \text { for } \nu>0 \\
& =C_{i}^{-}(-\nu) \text { for } \nu<0
\end{aligned}
$$

where $C_{i}^{+}$and $C_{i}^{-}$are defined over positive scalars, increasing and convex. One may expect $C_{i}^{+} \leq C_{i}^{-}$and the same inequality for the marginal costs. We only consider transactions $x$ that do not modify the sign of the positions towards the CCP, i.e. $|x| \leq\left|\nu_{i}\right|$.

The transaction affects differently the net positions of the seller and the buyer. Consider first the buyer. The incremental cost following transaction $x$ is equal to:

$$
\Delta C_{i}(x)=C_{i}\left(\nu_{b, i}+x\right)-C_{i}\left(\nu_{b, i}\right) .
$$

percent. In their simulations, Anderson and Joeveer (2014) evaluate the initial margins by 2.33 multiplied by the standard error of the absolute value of the notional.

${ }^{14}$ Anderson and Joeveer (2014) point out that CCPs may also differ in the type and quality of the required collateral. For example a 'regional' CCP may accept regional collateral that are not accepted by a global one. The two CCPs considered here are global and accept similar collateral baskets, each included in the ECB basket of securities eligible for refinancing.

${ }^{15}$ Since we consider three index CDS, with slightly different characteristics hence possibly different margin levels, we could also differentiate according to the traded product by adjusting $x$ by a multiplicative constant associated with the cleared product.

${ }^{16}$ We have no access to the full portfolio itself. By considering net positions, we abstract from the correlation between the different products, correlation that is used for computing the margins due to multi-netting. 
A simple specification for $C_{i}$ is a piece-wise linear function: $C_{i}^{+}(\nu)=c_{i}^{+} \nu$ and $C_{i}^{-}(\nu)=$ $c_{i}^{-} \nu$. In that case, the incremental cost is equal to $x\left(c_{i}^{+} \mathbb{1}_{\nu_{b, i}>0}-c_{i}^{-} \mathbb{1}_{\nu_{b, i}<0}\right)$ which, using $\mathbf{1}_{\nu_{b, i}>0}+\mathbf{1}_{\nu_{b, i}<0}=1$, is equal to

$$
\Delta C_{i}(x)=-c_{i} x \mathbb{1}_{\nu_{b, i}<0}+c t e
$$

where $c_{i}=c_{i}^{+}+c_{i}^{-}$and cte is a constant.

To test whether CCPs discriminate dealers according to their riskiness, we assume that each dealer is charged, on top of $C_{i}$, an additional margin (which can be negative) that is increasing in Spread, the deviation of its spread to the average spread over the dealers. Under a linear specification for the add-on, the term $c_{i}$ in (4) becomes $\alpha_{i}$ Spread $_{b}$. That is, the incremental premium charged to a buyer clearing on $\mathrm{CCP}_{i}$ is equal to

$$
-\alpha_{i} \operatorname{Spread}_{b} \mathbf{1}_{\nu_{b, i}<0} x+c t e
$$

where cte is a constant. For a seller, the incremental collateral costs are obtained by replacing $x$ by $-x$.

An alternative specification for the cost $C_{i}$ is a piece-wise quadratic and convex function. Taking first order approximations, we obtain

$$
\Delta C_{i}(x)=x \nu_{b, i}\left(c_{i}^{+} \mathbb{1}_{\nu_{b, i}>0}-c_{i}^{-} \mathbb{1}_{\nu_{b, i}<0}\right)
$$

which will lead us to use the gap as a explanatory variables.

So far, we have considered each dealer in a transacting pair separately. The decision made by the pair depends on the decision process between the buyer and seller. One assumption is that the traders choose the CCP achieving the smallest total cost (up to the fixed effects); another one is that either the buyer or the seller chooses the CCP. These assumptions are tested. ${ }^{17}$

\subsection{Results}

We estimate a discrete choice model (Logit) of CCP by pairs of dealers. Based on the previous section, our main objective is to test whether the differences in fees, riskiness of

\footnotetext{
${ }^{17}$ Our analysis differs from matching models, which also consider pairs. They primarily focus on which pairs form whereas we focus on pairs' decisions once they are formed, i.e. have undertaken a transaction.
} 
the CCPs and collateral costs are drivers of pairs' choices. The logit specification tests the choice of $\mathrm{CCP}_{2}$ against $\mathrm{CCP}_{1}$. The probability of choosing $\mathrm{CCP}_{2}$ against $\mathrm{CCP}_{1}$ by a pair $b, s$ conditional on the characteristics $X$, denoted by $\mathbb{P}\left(y_{b, s}=2 \mid X\right)$, satisfies

$$
\log \left(\frac{\mathbb{P}\left(y_{b, s}=2 \mid X\right)}{1-\mathbb{P}\left(y_{b, s}=2 \mid X\right)}\right)=X \beta
$$

Our benchmark model builds on the assumptions that the pair compares the sum of the incremental costs incurred by the pair on each CCP, and that collateral costs are piecewise linear. Overall, we find that dealers' choice of CCP relates to the fees, the CCPs ratios and the Vstoxx, but not to the collateral costs.

In our benchmark model, the probability of choosing $\mathrm{CCP}_{2}$ against $\mathrm{CCP}_{1}$ is an increasing function of the differences in the pair's incremental costs of choosing $\mathrm{CCP}_{2}$ rather than $\mathrm{CCP}_{1}$. Collecting terms in (2) (3), (4) and (5), $X \beta$ writes as

$$
\begin{array}{r}
2\left(f_{1}-f_{2}\right) x \\
+2 \alpha \delta\left(\frac{D F}{\text { Cover } 2}\right)+2 \beta \delta\left(\frac{D F+I M}{O I}\right)-2\left(\gamma_{2}-\gamma_{1}\right) \text { Vstoxx } \\
+x c_{1}\left(\mathbf{1}_{\nu_{s, 1}<0}-\mathbf{1}_{\nu_{b, 1}<0}\right)-x c_{2}\left(\mathbf{1}_{\nu_{s, 2}<0}-\mathbf{1}_{\nu_{b, 2}<0}\right)
\end{array}
$$

with $\delta\left(\frac{D F}{\text { Cover } 2}\right)=\left(\frac{D F}{\text { Cover } 2}\right)_{2}-\left(\frac{D F}{\text { Cover } 2}\right)_{1}$ and $\delta\left(\frac{D F+I M}{O I}\right)=\left(\frac{D F+I M}{O I}\right)_{2}-\left(\frac{D F+I M}{O I}\right)_{1}$.

$X$ thus includes the following explanatory variables: (1) the notional of transaction $x$ to control for the difference in fees, (2) the differences in CCPs ratios and the volatility index, and (3) the pair indices at each CCP to reflect the variation in pair's collateral cost for the pair and a pair index weighted by the spread of the dealers to account for discriminatory pricing.

Table 7 reports the baseline estimations. All specifications include a product fixed effect to account for differences in preference between products common across all dealers. They also include a pair of dealers-year ${ }^{18}$ fixed effect to remove unobservables on every dealers' pair and year combination that could impact the choice of CCP. These include among others the geographic segmentation, and the relations between the dealers and the CCPs that the CDS spreads fail to capture. We report estimates with robust standard errors. Lets us examine the coefficients in turn. The notional negatively relates to the

\footnotetext{
${ }^{18}$ Since Cover2 and prefunded ratios are available at a quarterly frequency, time-fixed effect cannot have a higher frequency.
} 
choice of $\mathrm{CCP}_{2}$. This relation is statistically significant in every specification and suggests differences in fees between $\mathrm{CCP}_{2}$ and $\mathrm{CCP}_{1}$.

The coefficient of the difference in prefunded ratios is significant and negative. As discussed in Section 4.1, a negative coefficient can be explained by a deterioration of the pool of the CCPs members, clients or products. The coefficient on the difference in Cover2 ratios is significant and positive, which suggests that dealers value CCP's robustness. Including the two ratios in specification (6) does not change their respective signs and magnitudes found in specifications (2) to (5). The Vstoxx coefficient is significant and negative in every specification, meaning that dealers tend to choose $\mathrm{CCP}_{2}$ less when volatility is higher $\left(\gamma_{2}-\gamma_{1}>0\right)$. A possible explanation is that $\mathrm{CCP}_{2}$ increases more than its collateral requirement in turbulent times. This effect is not captured by the ratios, since they are computed on a quarterly basis.

According to the model, we expect the coefficient of the pair index of $\mathrm{CCP}_{1}$ (resp. $\mathrm{CCP}_{2}$ ) to be positive (resp. negative). The relation between the choice of CCP and the pair index is either not significant for $\mathrm{CCP}_{2}$ or of opposite sign to the model's prediction for $\mathrm{CCP}_{1}$. These results hold across all specifications. Finally, the dealers' spreads interacted with the notional are never significant, probably because there is too much co-linearity with the notional itself, so we choose to include only the spreads without the notional. The signs of the buyer and seller's spreads are respectively negative and positive as expected, but only significant for the buyer.

To gauge the economic effect of variables on the choice of CCP, we compute how a variable larger than the mean by one standard deviation changes the probability of choosing $\mathrm{CCP}_{2}$ (in what follows 'larger' means 'larger than the mean by one standard deviation). ${ }^{19}$ A larger notional decreases the probability of choosing $\mathrm{CCP}_{2}$ by $1.6 \%$. The economic magnitude is larger for changes in the CCPs ratios. A larger difference in the prefunded ratios decreases the probability of choosing $\mathrm{CCP}_{2}$ by $3.9 \%$, while a larger difference in the Cover2 ratios increases it by $8.2 \%$. Finally, a larger Vstoxx decreases the probability of choosing $\mathrm{CCP}_{2}$ by $5.7 \%$.

The relation between the choice of CCP and the cost of collateral calls for further analysis. As the dealers' variables related to the cost of collateral (pair index and gap) change on a daily frequency, a time fixed effect at a higher frequency suits better for an accurate control of dealers' unobservables that may vary over time. In the following, we

\footnotetext{
${ }^{19}$ The reference probability of choosing $\mathrm{CPP}_{2}$ is evaluated at the mean value of all variables and fixed effects.
} 
restrict the analysis of the choice of CCP to the cost of collateral using either the pair index or the gap in net positions described at the beginning of the section. Overall, we still do not find evidence that the cost of collateral affects the choice of CCP for clearing a transaction.

We include a product fixed effect in every specification from Table 10 to 14 . In addition, we include either an individual-time fixed effect or two separate fixed effects, one for individuals, and one for time. Individual means either a pair of dealers, the seller or the buyer. As explained above, the individual-time fixed effect removes unobservables in the choice of CCP for all individuals at all periods. The time frequency is either monthly of weekly. The separate individual plus time fixed effects removes unobservables for all individuals and for all periods. The individual plus time fixed effects models a common trend in the unobservable dealers' differences. We report estimates with robust standard errors for individual-time fixed effects and with standard errors clustered at the individual level for individual plus time fixed effects.

If costs are linear in the positions, then the pair index should relate to the choice of CCP. Contradicting the predictions from the benchmark model, the relation between the choice of CCP and the pair indices is negative and significant at the $10 \%$ level in only two specifications. In the model, the decision bears on the total utilities, in particular on the pair's incremental costs. ${ }^{20}$ In practice, the decision might be always left to the seller or to the buyer. Therefore, we restrict the pair index to either the buyer or the seller in estimations (6) and (7). The pair index is still not significant for these estimations. To account for netting across products, we present the same specifications with net positions computed on the dealers' portfolios on all indices in Table 13. Likewise, we do not find evidence that dealers' pair indices relate to the choice of CCP. The relation between the notional and the choice of CCP is negative in all specifications from both tables and significant with pair-week fixed effects only. Its magnitude is similar to the one from the baseline estimations. Still, this tends to signal differences in fees schedules between the two CCPs. The Vstoxx is significant for month fixed effects only with a similar magnitude than in the benchmark results.

If dealers seek to equalize their positions between the two CCPs, then their gap in net positions relates to the choice of CCP. Still, estimations in Tables 11 and 12 in-

\footnotetext{
${ }^{20}$ One may argue that the seller makes the choice, since the cost of collateral for a single transaction is mainly borne by the seller. This neglects the fact that the collateral is not set per transaction, but based on the dealer's portfolio.
} 
clude individual-time or individual plus time fixed effects. We expect the seller's gap, $\delta\left(\nu_{s}\right)=\nu_{s, 2}-\nu_{s, 1}$, to positively relate to the choice of $\mathrm{CCP}_{2}$, and the buyer's gap to negatively relate. We indeed observe that the coefficient on the seller's gap is positive for all specifications. It is significant in the estimations with both buyer and seller's gaps, but not in specifications (3) and (6) where only the seller's gap and spread is tested. However, the coefficient on the buyer's gap is also positive. The buyer's gap is not significant in estimation (1), carried out with both buyer and sellers' gaps and pair-time fixed effects, but it is significant in the other specifications. Its positive sign contradicts the predictions derived from the model. Table 12 considers the dealer spread instead of the spread interacted with the dummies on net positions. It leaves the coefficients on the gap on net positions unchanged. We aggregate net positions for all index CDS in Table 14. Buyer's and seller's gaps in net positions are never significant for this set of estimations. The relation between the notional and the choice of CCP is still negative and significant in the majority of the specifications. The Vstoxx is only significant in specification (2) from Tables 11 and 12, and it has a similar magnitude than in the benchmark results. 


\begin{tabular}{|c|c|c|c|c|c|c|}
\hline & \multicolumn{5}{|c|}{ Dependent variable: } & \multirow[b]{3}{*}{ (6) } \\
\hline & \multirow[b]{2}{*}{ (1) } & \multicolumn{4}{|c|}{ CCP_choice } & \\
\hline & & (2) & (3) & (4) & (5) & \\
\hline$x$ & $\begin{array}{c}-0.0019^{*} \\
(0.001)\end{array}$ & $\begin{array}{c}-0.002^{* *} \\
(0.001)\end{array}$ & $\begin{array}{c}-0.0021^{* *} \\
(0.001)\end{array}$ & $\begin{array}{c}-0.0019^{*} \\
(0.001)\end{array}$ & $\begin{array}{c}-0.002^{* *} \\
(0.001)\end{array}$ & $\begin{array}{c}-0.002^{* *} \\
(0.001)\end{array}$ \\
\hline$\left(\mathbf{1}_{\nu_{s, 2}<0}-\mathbf{1}_{\nu_{b, 2}<0}\right) x$ & $\begin{array}{c}-8 \mathrm{e}-04 \\
(9 \mathrm{e}-04)\end{array}$ & $\begin{array}{c}-7 \mathrm{e}-04 \\
(9 \mathrm{e}-04)\end{array}$ & $\begin{array}{l}-9 \mathrm{e}-04 \\
(9 \mathrm{e}-04)\end{array}$ & $\begin{array}{l}-8 \mathrm{e}-04 \\
(0.001)\end{array}$ & $\begin{array}{c}-9 \mathrm{e}-04 \\
(0.001)\end{array}$ & $\begin{array}{l}-9 \mathrm{e}-04 \\
(0.001)\end{array}$ \\
\hline$\left(\mathbf{1}_{\nu_{s, 1}<0}-\mathbf{1}_{\nu_{b, 1}<0}\right) x$ & $\begin{array}{c}-0.0015^{*} \\
(9 \mathrm{e}-04)\end{array}$ & $\begin{array}{c}-0.0016^{*} \\
(9 \mathrm{e}-04)\end{array}$ & $\begin{array}{c}-0.0015^{*} \\
(9 \mathrm{e}-04)\end{array}$ & $\begin{array}{c}-0.0017^{*} \\
(9 \mathrm{e}-04)\end{array}$ & $\begin{array}{c}-0.0015^{*} \\
(9 \mathrm{e}-04)\end{array}$ & $\begin{array}{c}-0.0016^{*} \\
(9 \mathrm{e}-04)\end{array}$ \\
\hline$\delta\left(\frac{D F+I M}{O I}\right)$ & & $\begin{array}{c}-1.444^{* * *} \\
(0.2318)\end{array}$ & $\begin{array}{c}-1.4599^{* * *} \\
(0.2324)\end{array}$ & & & $\begin{array}{c}-0.8291^{* * *} \\
(0.2345)\end{array}$ \\
\hline$\delta\left(\frac{D F}{\text { Cover } 2}\right)$ & & & & $\begin{array}{c}0.0501^{* * *} \\
(0.0066)\end{array}$ & $\begin{array}{c}0.0504^{* * *} \\
(0.0066)\end{array}$ & $\begin{array}{c}0.04^{* * *} \\
(0.007)\end{array}$ \\
\hline $\operatorname{Spread}_{s}\left(\mathbf{1}_{\nu_{s, 2}<0}-\mathbf{1}_{\nu_{s, 1}<0}\right)$ & & & $\begin{array}{c}6 \mathrm{e}-04 \\
(0.0016)\end{array}$ & & $\begin{array}{c}5 \mathrm{e}-04 \\
(0.0016)\end{array}$ & $\begin{array}{c}3 \mathrm{e}-04 \\
(0.0015)\end{array}$ \\
\hline $\operatorname{Spread}_{b}\left(\mathbf{1}_{\nu_{b, 2}<0}-\mathbf{1}_{\nu_{b, 1}<0}\right)$ & & & $\begin{array}{c}-0.0047^{* * *} \\
(0.0017)\end{array}$ & & $\begin{array}{c}-0.0047^{* * *} \\
(0.0017)\end{array}$ & $\begin{array}{c}-0.0048^{* * *} \\
(0.0017)\end{array}$ \\
\hline Vstoxx & $\begin{array}{c}-0.0227^{* * *} \\
(0.0032)\end{array}$ & $\begin{array}{c}-0.0216^{* * *} \\
(0.0031)\end{array}$ & $\begin{array}{c}-0.021 * * * \\
(0.0031)\end{array}$ & $\begin{array}{c}-0.019^{* * *} \\
(0.0029)\end{array}$ & $\begin{array}{c}-0.0184^{* * *} \\
(0.0029)\end{array}$ & $\begin{array}{c}-0.0186^{* * *} \\
(0.0029)\end{array}$ \\
\hline Product FE & $\mathrm{Y}$ & $\mathrm{Y}$ & $\mathrm{Y}$ & $\mathrm{Y}$ & $\mathrm{Y}$ & $\mathrm{Y}$ \\
\hline Pair x year FE & $\mathrm{Y}$ & $\mathrm{Y}$ & $\mathrm{Y}$ & $\mathrm{Y}$ & $\mathrm{Y}$ & $\mathrm{Y}$ \\
\hline Observations & 14328 & 14328 & 14328 & 14328 & 14328 & 14328 \\
\hline Robust SE & $\mathrm{Y}$ & $\mathrm{Y}$ & $\mathrm{Y}$ & $\mathrm{Y}$ & $\mathrm{Y}$ & Y \\
\hline
\end{tabular}

Table 7 - CCP choice baseline results

The Logit estimation runs on the reduced sample of EU inter-dealer transactions. The sample period is from 2018Q3 to 2020Q3. Standard errors are robust and are given in parenthesis. ${ }^{* * *},{ }^{* *}$, and ${ }^{*}$ denote significance at the $1 \%, 5 \%$, and $10 \%$ level respectively.

\section{Concluding remarks}

In this paper, we shed light on the market structure of central counterparties using EU data. First, we describe the business model of CCPs. A variety of tools called the CCP 'policy' interact to set CCPs price and quality. This added to the two-tiered structure of clearing makes it difficult to apply textbook competition frameworks to the market for 
clearing. Second, we provide anecdotal evidence of both horizontal and vertical differentiation using public data on EU CCPs. Third, we focus on the dealers' demand for clearing using interdealer transactions from the CDS market. We highlight some geographic segmentation in the choice of CCP and show a substantial proportion of dealers' pair use only one CCP for clearing. To study how pairs of dealers choose CCPs to clear their transactions, we build a toy model and estimate it. We find that pairs' choices relate to the fees and riskiness of CCPs, to the volatility of the market but not to the collateral costs.

Besides debates on fees and netting efficiency, the market structure of central clearing is important because it is likely to have large implications for financial stability. Horizontal differentiation between CCPs such as geographic or specialized lines of products limits the pooling of institutions' idiosyncratic risks. In contrast, vertical differentiation on the quality of the clearing service contradicts the existence of a 'race-to-the-bottom' on collateral required by CCPs. These subjects are left for further research. 


\section{References}

Abbruzo, N., \& Park, Y.-H. (2016). An Empirical Analysis of Futures Margin Changes: Determinants and Policy Implications. Journal of Financial Services Research, 49 (1), 65-100.

Abad, J., Aldarosa, I., Aymanns, C., D'Errico, M., Rousova, L. F., Hoffmann, P., Langfield, S., Neychev, M., \& Roukny, T. (2016) Shedding light on dark markets: First insights from the new EU-wide OTC derivatives dataset ESRB Occasional Paper Series No 11.

Amini, H., Filipovic, D., \& Minca, A. (2015). To Fully Net or Not to Net: Adverse Effects of Partial Multilateral Netting. Operations Research, 64(5), 1053-1176.

Anderson, R. W., \& Joeveer, K. (2014). The economics of collateral. Available at SSRN 2427231.

Armakola, A., \& Laurent, J.-P. (2015). CCP Resilience and Clearing Membership.

Bellia, M., Panzica, R. Pelizzon, L. \& Peltonen, T. A., (2018) The Demand for Central Clearing: To Clear or Not to Clear, That Is the Question) Safe W.P No. 193.

Boissel, C., Derrien, F., Ors, E., \& Thesmar, D. (2017). Systemic risk in clearing houses: Evidence from the European repo market. Journal of Financial Economics, 125(3), 511-536.

Cantillon, E., \& Yin, P. L. (2008). Competition between Exchanges: Lessons from the Battle of the Bund. SSRN.

Coeuré, B.,(2014). Central counterparty recovery and resolution. Keynote speech at "Central clearing - guarantee of stability or new moral hazard?.

Committee on Payment and Settlement Systems (2010): Market structure developments in the clearing industry: implications for financial stability.

Cont, R., \& Kokholm, T. (2014). Central clearing of OTC derivatives: Bilateral vs multilateral netting. Statistics and Risk Modeling, 31(1), 3-22.

DFWS Reform (2010). Dodd-Frank Wall Street Reform and Consumer Protection Act Title VI.

Du, W., Gadgil, S., Gordy, M. B. \& Vega, C. (2019). Counterparty Risk and Counterparty Choice in the Credit Default Swap Market, SSRN.

Duffie, D., Scheicher, M., \& Vuillemey, G. (2015). Central clearing and collateral demand. Journal of Financial Economics, 116(2), 237-256.

Duffie, D., \& Zhu, H. (2011). Does a central clearing counterparty reduce counterparty risk?. Review of Asset Pricing Studies, 1(1), 74-95. 
Elliott, D. (2013). Central counterparty loss-allocation rules. Bank of England Financial Stability Paper, 20, 16.

EMIR (2012). Regulation (EU) No 648/2012 of the European Parliament and of the Council of 4 July 2012 on OTC derivatives, central counterparties and trade repositories.

Fleming, M., J., \& Sarkar, A. (2014). The Failure Resolution of Lehman Brothers. Federal Reserve Bank of New York Economic Policy Review, 20(2), 175-206.

Financial Times (2018). Trader blows $€ 100 \mathrm{mn}$ hole in Nasdaq's Nordic power market.

Ghamami, S., \& Glasserman, P. (2017). Does OTC derivatives reform incentivize central clearing? Journal of Financial Intermediation, 32, 76-87.

Glasserman, P., Moallemi, C. C., \& Yuan, K. (2015). Hidden illiquidity with multiple central counterparties. Operations Research, 64(5), 1143-1158.

Pirrong C. (2011). The Economics of Central Clearing: Theory and Practice, ISDA Discussion Paper Series, 1.

United States Department of Justice (DOJ) (2007), Review of the Regulatory Structure Associated with Financial Institutions, in response to Department of the Treasury request TREAS-DO-2007-0018, http://www.usdoj.gov/atr/public/comments/229911.htm.

Vaghela, V. (2014). Korea clearing structure in question after HanMag trading error, Risk Net. Vuillemey G. (2019). The Value of Central Clearing, Journal of Finance, 75, 2021-2053.

Zhu S. (2011). Is there a "race to the bottom" in central counterparties competition?, DNB Occasional Studies. 


\section{Appendix}

\subsection{Geographical differentiation}

The next figure presents the contractual network between CCPs and their members for two classes of derivatives: interest rate (top) and credit (bottom) derivatives as of March 2017.
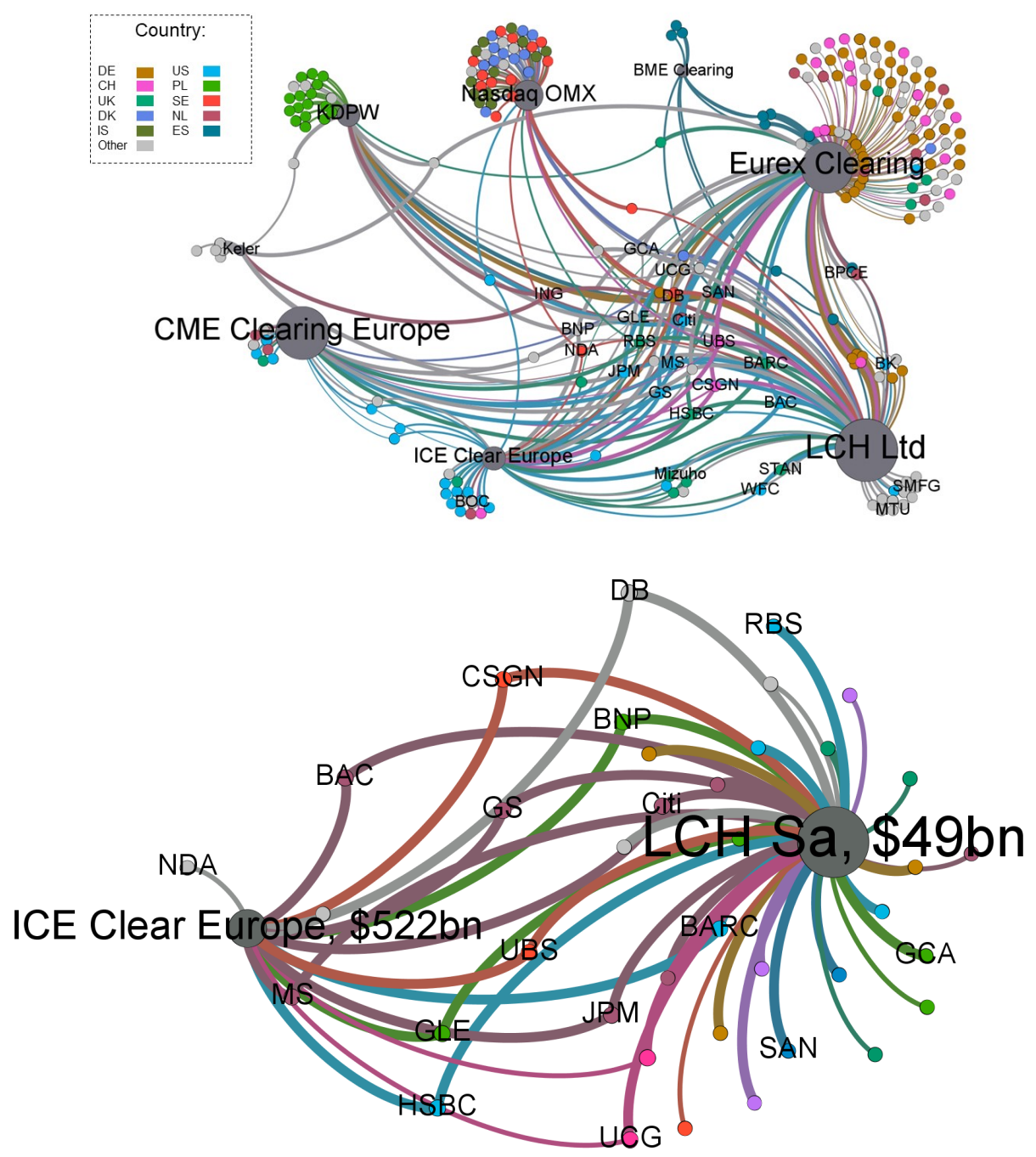

Figure 6 - Interest rate derivatives (top) CDS (bottom) contractual networks

Nodes are colored according to members countries (see legend), and CCPs are colored in dark grey. Source: CCPs disclosure, as of March 2017. CME Clearing is no longer active in Europe. 
We have access to information on the existing contractual linkages between European clearinghouses and their members and the members' customers (but not to the volumes) for some products such as the CDS. Only two EU CCPs are authorized to clear CDSs under EMIR: ICE Clear Europe and LCH SA. They share 14 common counterparties, all of them being major systemic institutions (G-SIB banks as defined by the Financial Stability Board) except for Intesa San Paolo. They are labelled on the picture (JPM stands for J.P. Morgan for example), while the thickness of edges is changed according to the type of membership.

In addition to the market shares on Index CDS from Figure 4 and the indices eligible for clearing in Figure 7, the market for single name CDS also highlights substantial segmentation between CCP. Clearing of single name CDS in Table 8 reveals that the two CCPs offer clearing for $1 / 3$ of single name instruments, but $2 / 3$ of them are eligible for clearing at a single CCP, stressing the existence of local monopolies.

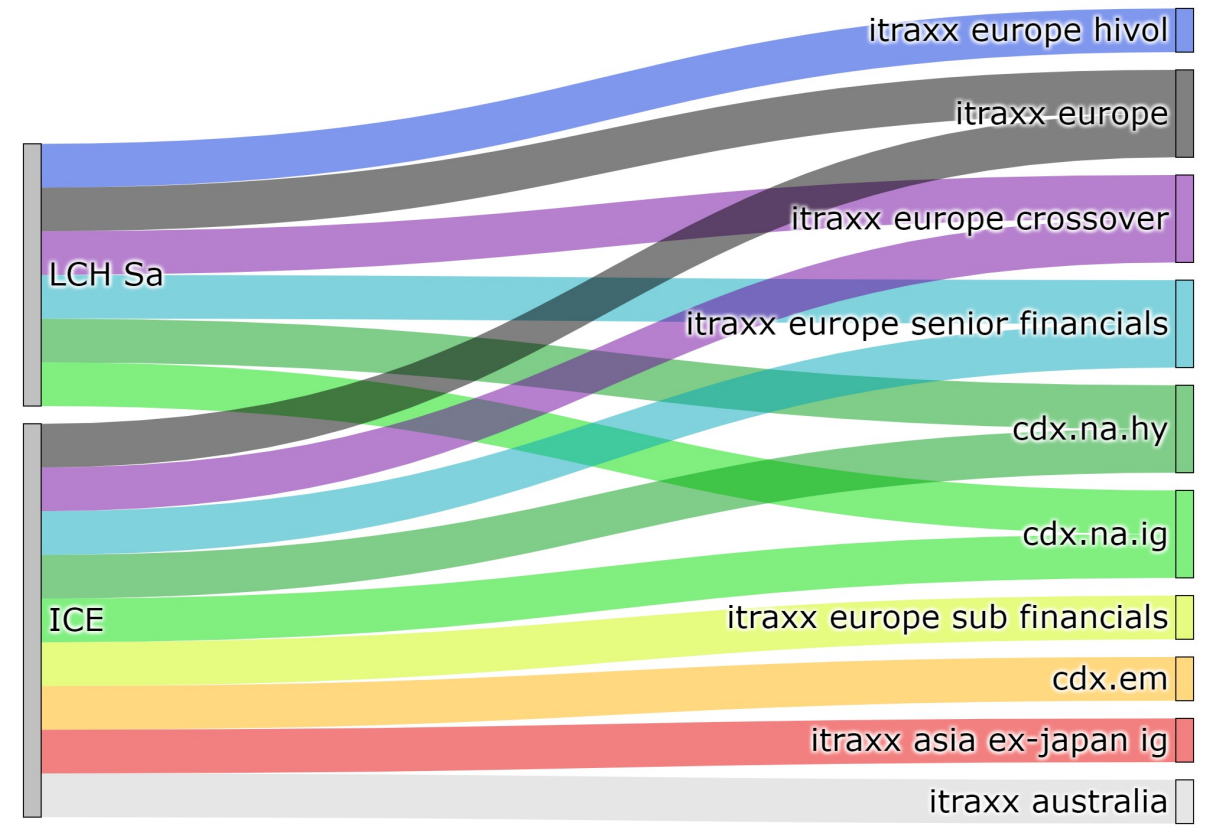

Figure 7 - Product line differentiation: Index CDS eligible for clearing

Sankey diagram of Index CDS eligible for clearing between LCH SA and ICE (group). Cdx.em, Itraxx Asia ex-japan ig and Itraxx Australia are eligible for clearing at ICE Clear Credit, and not ICE Clear Europe. Flows are colored according to the Index name. Source: CCPs disclosure, as of April 2019. 


\begin{tabular}{lrrr}
\hline Eligible products & LCH SA only & ICE (group) only & Both CCPs \\
\hline Number of products & 102 & 304 & 211 \\
\hline Open Interest (€billion) & & & \\
LCH SA & 15.8 & 0 & 72.3 \\
ICE (group) & 0 & 178.3 & 248.9 \\
\hline
\end{tabular}

Table 8 - Product line differentiation: single name CDS eligible for clearing

Source: CCPs' disclosure as of April 2019.

\subsection{Data cleaning}

As a French regulator, Banque de France has access to derivative transactions reported to Trade Repositories (TR) under EMIR. The scope of the French data is smaller than the European sample. It includes transactions with at least a French entity and transactions with at least one EU entity on French underlings. Because major indexes contain at least one French underlying, our dataset restricted to indexes covers all transactions with at least an EU entity.

We extract new transactions from trade activity reports. For consistency, we match transactions with different identifiers (Trade ID) but with similar economic characteristics (notional, execution date, maturity date, underlying). We also match transactions subject to mandatory clearing but with no CCP reported with transactions that have similar characteristics and that take place between a party of the transaction and a CCP.

We finally merge matched transactions and transactions with duplicate reporting in one-liner transactions. As in Abbad et al. (2016), we remove implausible notional, incorrect identifiers for underlying (either missing ISIN or wrong Index name), transactions without maturity date, intragroup transactions, transactions with non-LEI counterparties.

Even among products subject to the clearing obligation, no CCP is reported for a substantial proportion of transactions. The proportion does not vary significantly across products,${ }^{21}$ although clearing Itraxx Senior Financials is not mandatory. Removing those transactions, we lose $23 \%$ of total transactions and $19 \%$ of notional.

\footnotetext{
${ }^{21}$ For Itraxx Europe, $14 \%$ of EZ-EZ transactions have no CCP, $19 \%$ of EZ-GB have no CCP, and $23 \%$ of GB-GB have no CCP.
} 


\subsection{Figures and tables}

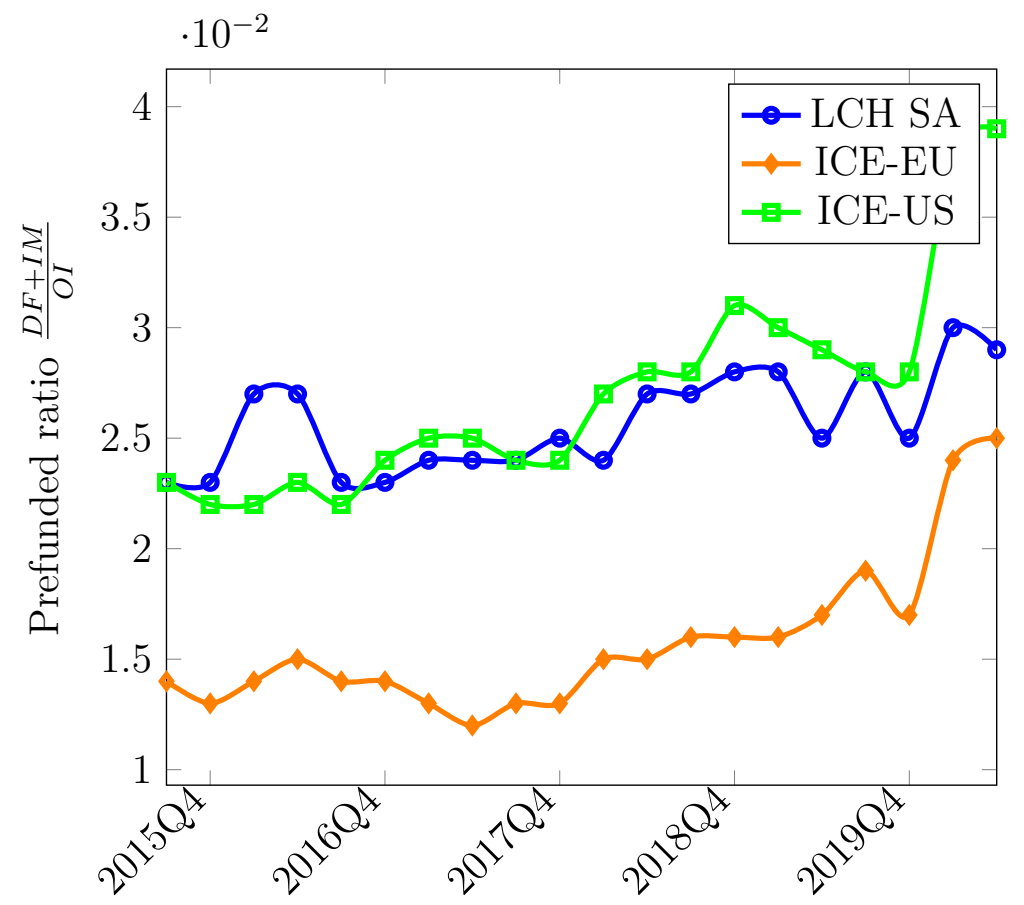

Figure 8 - Vertical differentiation: evolution of the prefunded ratio

The figure plots the quarterly evolution of LCH SA, ICE EU, ICE US prefunded ratios $\frac{D F+I M}{O I}$. Source: CCPs IOSCO quantitative disclosure from 2015Q3 to $2020 Q 2$. 


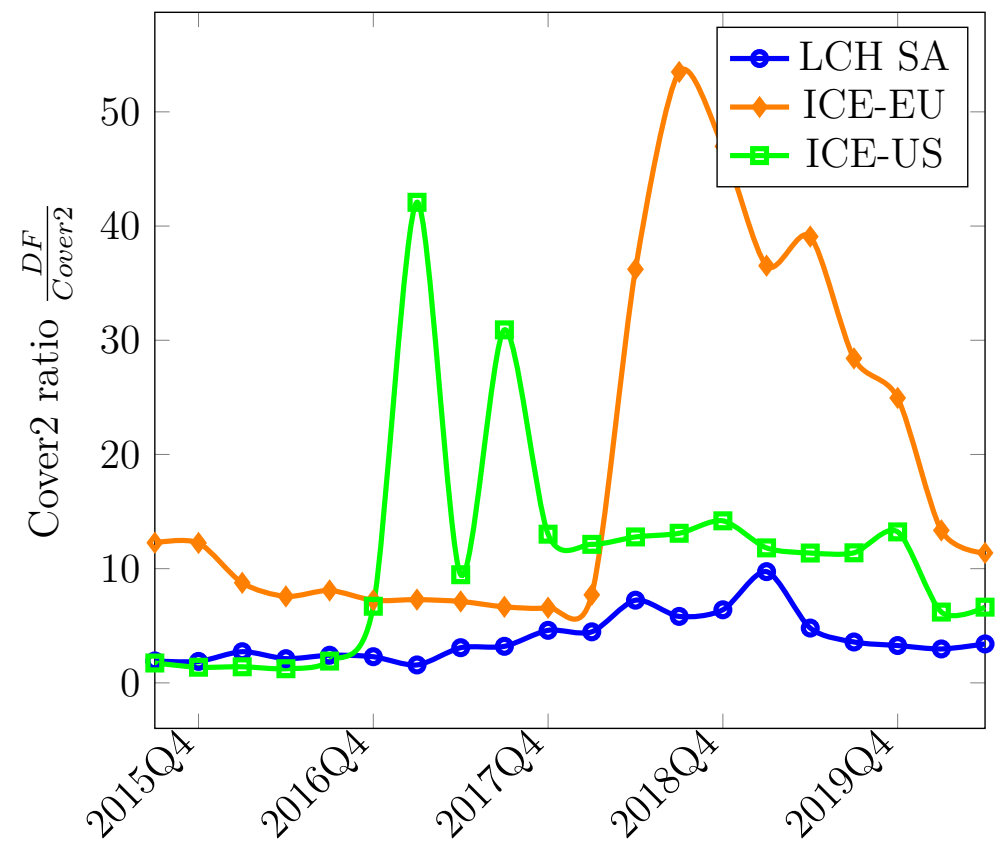

Figure 9 - Vertical differentiation: evolution of the Cover2 ratio The figure plots the quarterly evolution of LCH SA, ICE EU, ICE US Cover2 ratios $\frac{D F}{\text { Cover } 2}$. Source: CCPs IOSCO quantitative disclosure from 2015Q3 to 2020Q2.

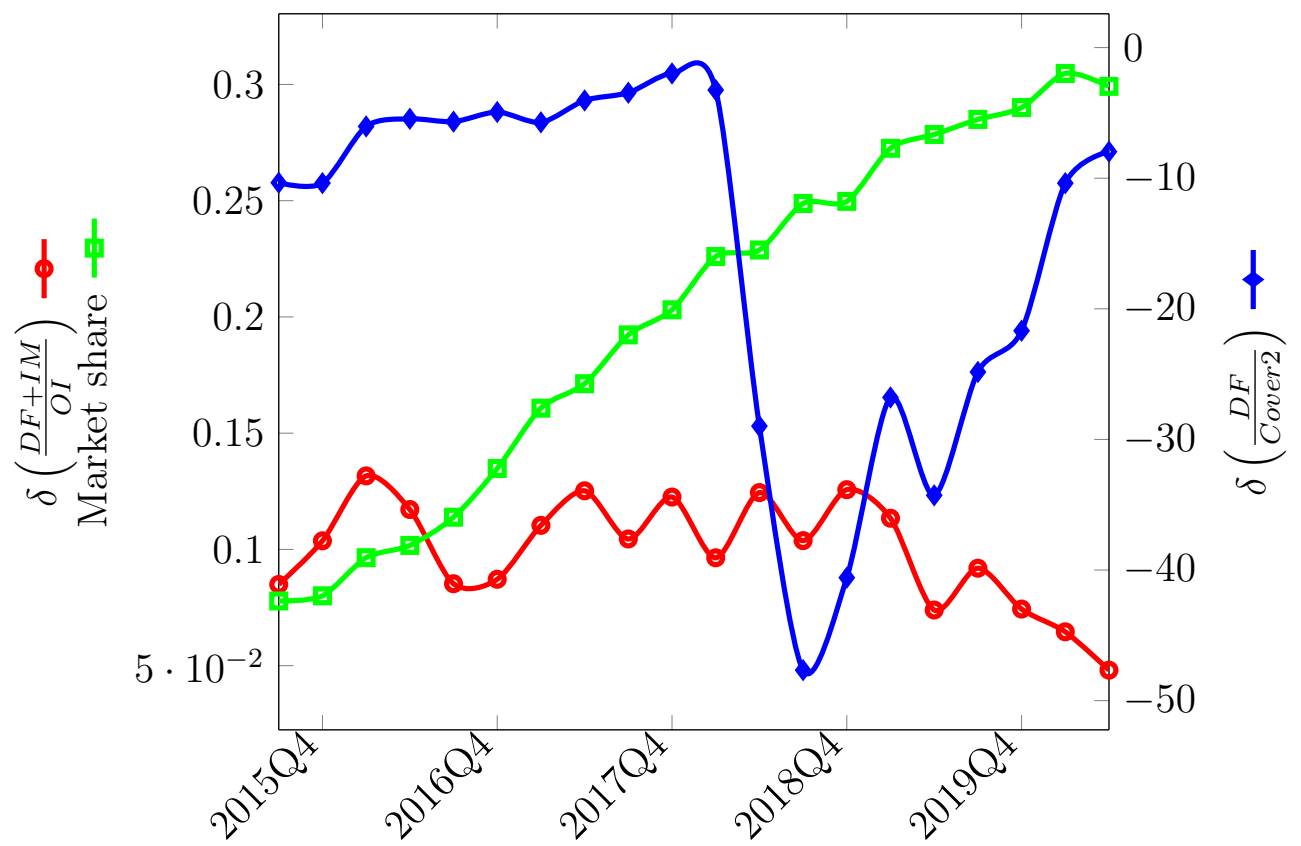

Figure 10 - LCH SA market share against ICE EU, differences in prefunded and Cover2 ratios

The figure plots the quarterly evolution of LCH SA market share against ICE EU, along with the difference in prefunded and Cover2 ratios between LCH SA and ICE EU. Source: CCPs IOSCO quantitative disclosure from $2015 Q 3$ to $2020 Q 2$. 


\begin{tabular}{|c|c|c|c|c|}
\hline Name & Country & LCH SA & ICE-EU & ICE-US \\
\hline Bank of America, Na & US & $\mathrm{X}$ & $\mathrm{X}$ & $\mathrm{X}$ \\
\hline Merrill Lynch International & GB & $\mathrm{X}$ & $\mathrm{X}$ & $\mathrm{X}$ \\
\hline Barclays Bank Plc & GB & $\mathrm{X}$ & $\mathrm{X}$ & $\mathrm{X}$ \\
\hline Bnp Paribas & FR & $\mathrm{X}$ & $\mathrm{X}$ & $\mathrm{X}$ \\
\hline Citigroup Global Markets Limited & GB & $\mathrm{X}$ & $\mathrm{X}$ & \\
\hline Citigroup Global Markets Inc & US & & $\mathrm{X}$ & $\mathrm{X}$ \\
\hline Citibank, National Association & US & & $\mathrm{X}$ & $\mathrm{X}$ \\
\hline Credit Suisse International & GB & $\mathrm{X}$ & $\mathrm{X}$ & $\mathrm{X}$ \\
\hline Deutsche Bank Aktiengesellschaft & $\mathrm{DE}$ & $\mathrm{X}$ & $\mathrm{X}$ & $\mathrm{X}$ \\
\hline Goldman Sachs International & GB & $\mathrm{X}$ & $\mathrm{X}$ & $\mathrm{X}$ \\
\hline HSBC Bank Plc & GB & $\mathrm{X}$ & $\mathrm{X}$ & $\mathrm{X}$ \\
\hline J.P. Morgan Secutities Plc & GB & $\mathrm{X}$ & $\mathrm{X}$ & \\
\hline JPMorgan Chase Bank, Na & US & & $\mathrm{X}$ & $\mathrm{X}$ \\
\hline Morgan Stanley \& CO. International Plc & GB & $\mathrm{X}$ & $\mathrm{X}$ & \\
\hline Morgan Stanley Capital Services LLC & US & & $\mathrm{X}$ & $\mathrm{X}$ \\
\hline Nomura International Plc & GB & & $\mathrm{X}$ & $\mathrm{X}$ \\
\hline Societe Generale & FR & $\mathrm{X}$ & $\mathrm{X}$ & X \\
\hline UBS AG & $\mathrm{CH}$ & & $\mathrm{X}$ & $\mathrm{X}$ \\
\hline
\end{tabular}

Table 9 - Active dealers' membership

To account for different geographical areas, we do not aggregate active dealers affiliated entities at the group level. Sources: GLEIF, and CCPs websites. 


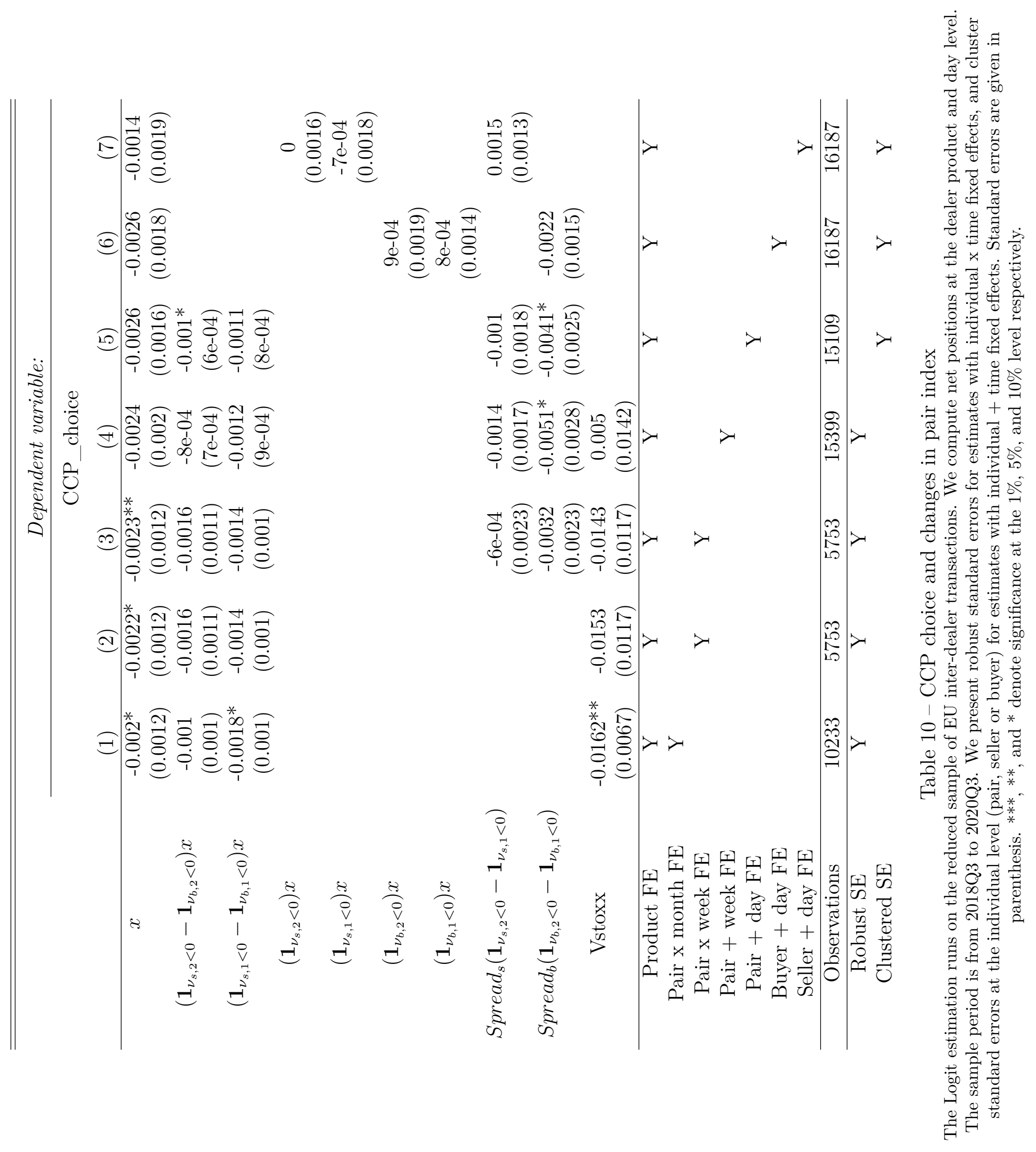




\begin{tabular}{|c|c|c|c|c|c|c|}
\hline & \multicolumn{6}{|c|}{ Dependent variable: } \\
\hline & \multicolumn{6}{|c|}{$\mathrm{CCP}_{2}$ choice } \\
\hline & $(1)$ & $(2)$ & $(3)$ & $(4)$ & $(5)$ & $(6)$ \\
\hline$x$ & $\begin{array}{c}-0.0027^{* * *} \\
(9 \mathrm{e}-04)\end{array}$ & $\begin{array}{c}-0.0016^{* *} \\
(8 \mathrm{e}-04)\end{array}$ & $\begin{array}{c}-0.0014^{*} \\
(7 \mathrm{e}-04)\end{array}$ & $\begin{array}{l}-0.0027^{*} \\
(0.0016)\end{array}$ & $\begin{array}{l}-0.0017 \\
(0.0011)\end{array}$ & $\begin{array}{r}-0.0018^{*} \\
(0.001)\end{array}$ \\
\hline \multirow{2}{*}{$\delta\left(\nu_{s}\right)$} & $0.0187^{* *}$ & & 0.0096 & $0.0194^{*}$ & & 0.0103 \\
\hline & $(0.0086)$ & & $(0.0062)$ & $(0.0117)$ & & $(0.0091)$ \\
\hline \multirow{2}{*}{$\delta\left(\nu_{b}\right)$} & 0.0119 & $0.0143^{* *}$ & & $0.0184^{*}$ & $0.013^{*}$ & \\
\hline & $(0.009)$ & $(0.007)$ & & $(0.0104)$ & $(0.007)$ & \\
\hline \multirow{2}{*}{$\operatorname{Spread}_{s}\left(\mathbf{1}_{\nu_{s, 2}<0}-\mathbf{1}_{\nu_{s, 1}<0}\right)$} & -0.001 & & -0.001 & $-9 e-04$ & & 0.0018 \\
\hline & $(0.0022)$ & & $(0.0016)$ & $(0.0018)$ & & $(0.0014)$ \\
\hline \multirow{2}{*}{$\operatorname{Spread}_{b}\left(\mathbf{1}_{\nu_{b, 2}<0}-\mathbf{1}_{\nu_{b, 1}<0}\right)$} & -0.0037 & $-7 \mathrm{e}-04$ & & $-0.0042^{*}$ & -0.0018 & \\
\hline & $(0.0023)$ & $(0.0014)$ & & $(0.0025)$ & $(0.0016)$ & \\
\hline \multirow[t]{2}{*}{ Vstoxx } & -0.0129 & $-0.0184^{* *}$ & -0.0026 & & & \\
\hline & $(0.0118)$ & $(0.0076)$ & $(0.0074)$ & & & \\
\hline Product FE & $\mathrm{Y}$ & $\mathrm{Y}$ & $\mathrm{Y}$ & $\bar{Y}$ & $\mathrm{Y}$ & $\mathrm{Y}$ \\
\hline Pair x week FE & $\mathrm{Y}$ & & & & & \\
\hline Buyer x week FE & & $\mathrm{Y}$ & & & & \\
\hline Seller $\mathrm{x}$ week FE & & & $\mathrm{Y}$ & & & \\
\hline Pair + day FE & & & & $\mathrm{Y}$ & & \\
\hline Buyer + day FE & & & & & $\mathrm{Y}$ & \\
\hline Seller + day FE & & & & & & $\mathrm{Y}$ \\
\hline Observations & 5753 & 13353 & 13233 & 15109 & 16187 & 16187 \\
\hline Robust SE & $\mathrm{Y}$ & $\mathrm{Y}$ & $\mathrm{Y}$ & & & \\
\hline Clustered SE & & & & $\mathrm{Y}$ & $\mathrm{Y}$ & $\mathrm{Y}$ \\
\hline
\end{tabular}

Table 11 - CCP choice and changes in differences in positions between $\mathrm{CCP}_{2}$ and $\mathrm{CCP}_{1}$ The Logit estimation runs on the reduced sample of EU inter-dealer transactions. We compute net positions at the dealer product and day level. The sample period is from 2018Q3 to 2020Q3. We present robust standard errors for estimates with individual $\mathrm{x}$ time fixed effects, and cluster standard errors at the individual level (pair, seller or buyer) for estimates with individual + time fixed effects. Standard errors are given in parenthesis. ${ }^{* * *},{ }^{* *}$, and ${ }^{*}$ denote significance at the $1 \%, 5 \%$, and $10 \%$ level respectively. 


\begin{tabular}{|c|c|c|c|c|c|c|}
\hline & \multicolumn{6}{|c|}{ Dependent variable: } \\
\hline & \multicolumn{6}{|c|}{ CCP_choice } \\
\hline & (1) & (2) & (3) & (4) & (5) & (6) \\
\hline$x$ & $\begin{array}{c}-0.0027^{* * *} \\
(9 \mathrm{e}-04)\end{array}$ & $\begin{array}{c}-0.0016^{* *} \\
(8 \mathrm{e}-04)\end{array}$ & $\begin{array}{c}-0.0013^{*} \\
(7 \mathrm{e}-04)\end{array}$ & $\begin{array}{c}-0.0027^{*} \\
(0.0016)\end{array}$ & $\begin{array}{c}-0.0018^{*} \\
(0.0011)\end{array}$ & $\begin{array}{c}-0.0019^{*} \\
(0.001)\end{array}$ \\
\hline$\delta\left(\nu_{s}\right)$ & $\begin{array}{l}0.0165^{*} \\
(0.0086)\end{array}$ & & $\begin{array}{c}0.0095 \\
(0.0062)\end{array}$ & $\begin{array}{c}0.0179 \\
(0.0117)\end{array}$ & & $\begin{array}{l}0.0103 \\
(0.009)\end{array}$ \\
\hline$\delta\left(\nu_{b}\right)$ & $\begin{array}{l}0.0114 \\
(0.009)\end{array}$ & $\begin{array}{c}0.0142^{* *} \\
(0.007)\end{array}$ & & $\begin{array}{c}0.0203^{* *} \\
(0.0096)\end{array}$ & $\begin{array}{l}0.0146^{* *} \\
(0.0067)\end{array}$ & \\
\hline Spread $_{s}$ & $\begin{array}{c}0.0064 \\
(0.0117)\end{array}$ & & $\begin{array}{l}-0.0083 \\
(0.0117)\end{array}$ & $\begin{array}{c}0.0011 \\
(0.0073)\end{array}$ & & $\begin{array}{l}-0.0028 \\
(0.0031)\end{array}$ \\
\hline Spread $_{b}$ & $\begin{array}{c}0.0058 \\
(0.0118) \\
(0.0118)\end{array}$ & $\begin{array}{c}0.001 \\
(0.0092) \\
(0.0092)\end{array}$ & & $\begin{array}{c}-0.0014 \\
(0.0067) \\
(0.0067)\end{array}$ & $\begin{array}{c}-0.0049^{* * *} \\
(0.0017) \\
(0.0017)\end{array}$ & \\
\hline Vstoxx & $\begin{array}{l}-0.0172 \\
(0.0132)\end{array}$ & $\begin{array}{c}-0.0188^{* *} \\
(0.008)\end{array}$ & $\begin{array}{c}-9 \mathrm{e}-04 \\
(0.008)\end{array}$ & & & \\
\hline Product FE & $\mathrm{Y}$ & $\mathrm{Y}$ & $\mathrm{Y}$ & $\mathrm{Y}$ & $\mathrm{Y}$ & $\mathrm{Y}$ \\
\hline Pair x week FE & Y & & & & & \\
\hline Buyer $\mathrm{x}$ week FE & & Y & & & & \\
\hline Seller $\mathrm{x}$ week FE & & & Y & & & \\
\hline Pair + day FE & & & & Y & & \\
\hline Buyer + day FE & & & & & Y & \\
\hline Seller + day FE & & & & & & $\mathrm{Y}$ \\
\hline Observations & 5753 & 13353 & 13233 & 15109 & 16187 & 16187 \\
\hline $\begin{array}{c}\text { Robust SE } \\
\text { Clustered SE }\end{array}$ & $\mathrm{Y}$ & $\mathrm{Y}$ & $\mathrm{Y}$ & Y & Y & Y \\
\hline
\end{tabular}

Table 12 - Robustness check: CCP choice and changes in differences in positions between $\mathrm{CCP}_{2}$ and $\mathrm{CCP}_{1}$ with $\mathrm{CDS}$ deviation only

The Logit estimation runs on the reduced sample of EU inter-dealer transactions. We compute net positions at the dealer product and day level. The sample period is from 2018Q3 to 2020Q3. We present robust standard errors for estimates with individual x time fixed effects, and cluster standard errors at the individual level (pair, seller or buyer) for estimates with individual + time fixed effects. Standard errors are given in parenthesis. ***, **, and * denote significance at the $1 \%, 5 \%$, and $10 \%$ level respectively. 


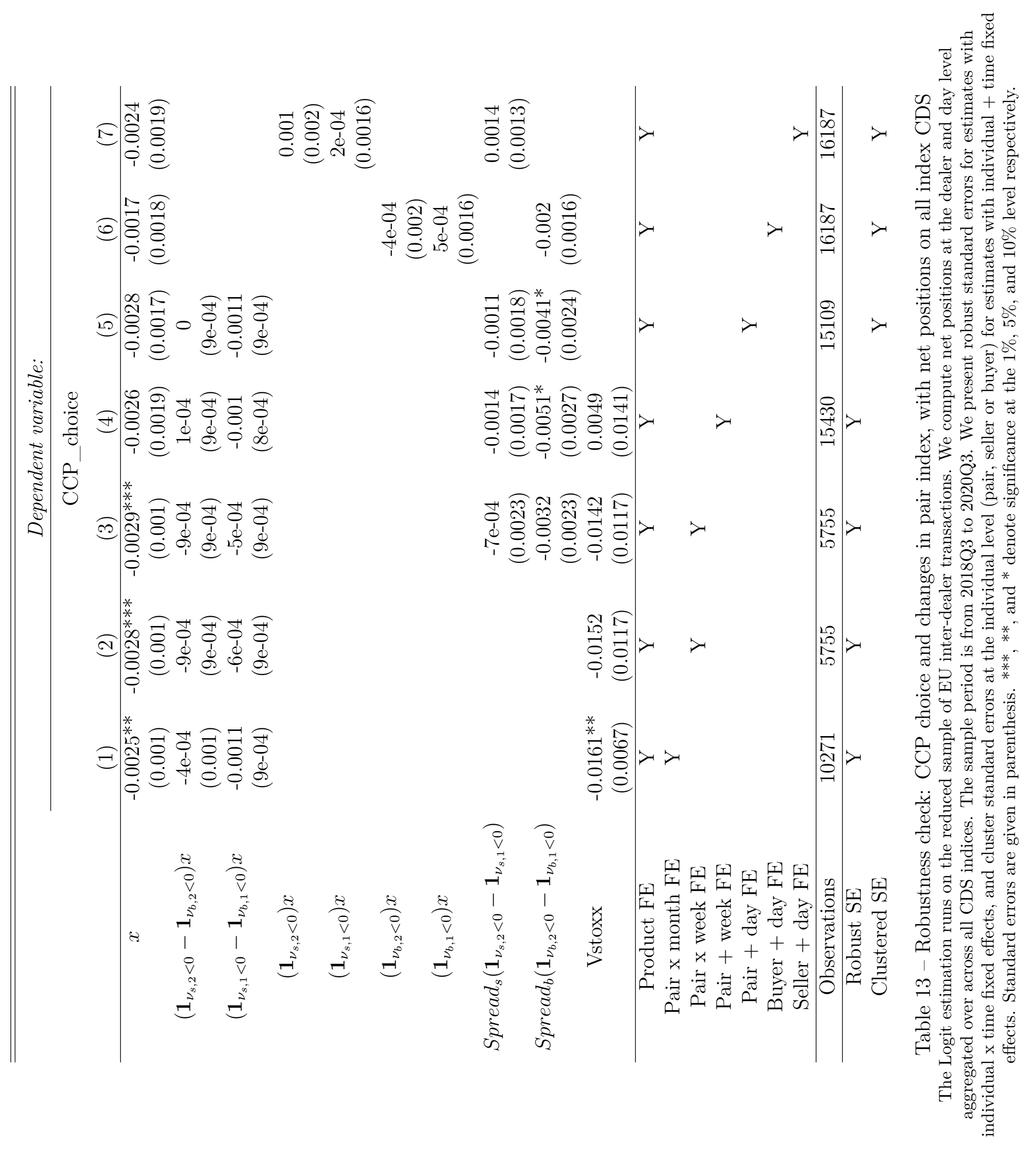




\begin{tabular}{|c|c|c|c|c|c|c|}
\hline & \multicolumn{6}{|c|}{ Dependent variable: } \\
\hline & \multicolumn{6}{|c|}{$\mathrm{CCP}$ _choice } \\
\hline & $(1)$ & $(2)$ & $(3)$ & $(4)$ & $(5)$ & $(6)$ \\
\hline$x$ & $\begin{array}{c}-0.0027^{* * *} \\
(9 \mathrm{e}-04)\end{array}$ & $\begin{array}{c}-0.0016^{* *} \\
(8 \mathrm{e}-04)\end{array}$ & $\begin{array}{c}-0.0013^{*} \\
(7 \mathrm{e}-04)\end{array}$ & $\begin{array}{l}-0.0027^{*} \\
(0.0016)\end{array}$ & $\begin{array}{l}-0.0017 \\
(0.0011)\end{array}$ & $\begin{array}{r}-0.0018^{*} \\
(0.001)\end{array}$ \\
\hline \multirow[t]{2}{*}{$\delta\left(\nu_{s}\right)$} & -0.0275 & & -0.0253 & 0.0098 & & 0.007 \\
\hline & $(0.0283)$ & & $(0.025)$ & $(0.0088)$ & & $(0.0067)$ \\
\hline \multirow[t]{2}{*}{$\delta\left(\nu_{b}\right)$} & -0.023 & 0.0221 & & 0.013 & 0.0079 & \\
\hline & $(0.0278)$ & $(0.0246)$ & & $(0.0104)$ & $(0.0065)$ & \\
\hline \multirow[t]{2}{*}{$\operatorname{Spread}_{s}\left(\mathbf{1}_{\nu_{s, 2}<0}-\mathbf{1}_{\nu_{s, 1}<0}\right)$} & $-9 \mathrm{e}-04$ & & -0.001 & $-4 \mathrm{e}-04$ & & 0.0019 \\
\hline & $(0.0023)$ & & $(0.0016)$ & $(0.0016)$ & & $(0.0014)$ \\
\hline \multirow[t]{2}{*}{$\operatorname{Spread}_{b}\left(\mathbf{1}_{\nu_{b, 2}<0}-\mathbf{1}_{\nu_{b, 1}<0}\right)$} & -0.003 & $-6 e-04$ & & -0.0034 & -0.0015 & \\
\hline & $(0.0024)$ & $(0.0014)$ & & $(0.0021)$ & $(0.0016)$ & \\
\hline \multirow[t]{2}{*}{ Vstoxx } & -0.0143 & $-0.018^{* *}$ & -0.0029 & & & \\
\hline & $(0.0118)$ & $(0.0076)$ & $(0.0074)$ & & & \\
\hline Product FE & $\mathrm{Y}$ & $\mathrm{Y}$ & $\mathrm{Y}$ & $\mathrm{Y}$ & $\mathrm{Y}$ & $\mathrm{Y}$ \\
\hline Pair x week FE & $\mathrm{Y}$ & & & & & \\
\hline Buyer $\mathrm{x}$ week FE & & $\mathrm{Y}$ & & & & \\
\hline Seller x week FE & & & $\mathrm{Y}$ & & & \\
\hline Pair + day FE & & & & $\mathrm{Y}$ & & \\
\hline Buyer + day FE & & & & & $\mathrm{Y}$ & \\
\hline Seller + day FE & & & & & & $\mathrm{Y}$ \\
\hline Observations & 5753 & 13353 & 13233 & 15109 & 16187 & 16187 \\
\hline Robust SE & $\mathrm{Y}$ & $\mathrm{Y}$ & $\mathrm{Y}$ & & & \\
\hline Clustered SE & & & & $\mathrm{Y}$ & $\mathrm{Y}$ & $\mathrm{Y}$ \\
\hline
\end{tabular}

Table 14 - Robustness check: CCP choice and changes in differences in positions between $\mathrm{CCP}_{2}$ and $\mathrm{CCP}_{1}$, with net positions on all index CDS.

The Logit estimation runs on the reduced sample of EU inter-dealer transactions. We compute net positions at the dealer summed across all index CDS and day level. The sample period is from 2018Q3 to 2020Q3. We present robust standard errors for estimates with individual $\mathrm{x}$ time fixed effects, and cluster standard errors at the individual level (pair, seller or buyer) for estimates with individual + time fixed effects. Standard errors are given in parenthesis. ${ }^{* * *},{ }^{* *}$, and ${ }^{*}$ denote significance at the $1 \%, 5 \%$, and $10 \%$ level respectively. 